\title{
The ratio between centromeric proteins CENP-A and CENP-C maintains homeostasis of human centromeres
}

\author{
Daniël P. Melters ${ }^{1, *}$, Tatini Rakshit ${ }^{1, *}$, Minh Bui ${ }^{1}$, Sergei A. Grigoryev ${ }^{2}$, David Sturgill ${ }^{1}$, and \\ Yamini Dalal ${ }^{1, \#}$
}

1 National Cancer Institute, Center for Cancer Research, Laboratory of Receptor Biology and Gene Expression, Bethesda, MD

\author{
2 Pennsylvania State University, College of Medicine, Hershey, PA \\ * Contributed equally \\ \# Corresponding author: dalaly@mail.nih.gov
}

Keyword: chromosome, mitosis, kinetochore, nucleosomes, chromatin, centromere

\begin{abstract}
The centromere is the chromosomal locus that seeds the kinetochore, allowing for a physical connection between the chromosome and the mitotic spindle. At the heart of the centromere is the centromere-specific histone H3 variant CENP-A/CENH3. Throughout the cell cycle the constitutive centromere associated network is bound to CENP-A chromatin, but how this protein network modifies CENP-A nucleosome dynamics in vivo is unknown. Here, we purify kinetochore associated native centromeric chromatin and analyze its biochemical features using a combinatorial approach. We report that kinetochore bound chromatin has strongly reduced DNA accessibility and a distinct stabilized nucleosomal configuration. Disrupting the balance between CENP-A and CENP-C result in reduced centromeric occupancy of RNA polymerase 2 and
\end{abstract}


impaired de novo CENP-A loading on the centromeric chromatin fiber, correlating with significant mitotic defects. CENP-A mutants that restore the ratio rescue the mitotic defects. These data support a model in which CENP-C bound centromeric nucleosomes behave as a barrier to the transcriptional machinery and suggest that maintaining the correct ratio between CENP-A and CENP-C levels is critical for centromere homeostasis.

\section{Introduction}

The kinetochore is a large proteinaceous complex which physically connects centromeric chromatin to the mitotic microtubule spindles. Inaccuracies in kinetochore assembly can lead to the formation of dicentric chromosomes, or chromosomes lacking kinetochores. In either case, chromosomes fail to segregate faithfully, which drives genomic instability. Electron microscopy studies of mitotic centromeres reveal a two-layered electron dense structure that is over $200 \mathrm{~nm}$ in width and over $50 \mathrm{~nm}$ in depth (Comings \& Okada, 1970; Rattner et al, 1975; Esponda, 1978; McEwen et al, 1998), delineated into the inner and outer kinetochore.

At the base of the inner kinetochore is the histone H3 variant CENP-A (CENH3), which is marked by its rapid evolution (Malik \& Henikoff, 2001, 2003; Talbert et al, 2004; Cooper \& Henikoff, 2004; Meraldi et al, 2006; Maheshwari et al, 2015), and its association with equally rapid evolving centromere DNA (Melters et al, 2013). This enhanced rate of evolution of sequences underlying the essential and conserved function is commonly referred to as the centromere paradox (Henikoff et al, 2001). Nevertheless, despite lack of sequence conservation at the level of CENP-A, and its associated DNA, in most species, CENP-A chromatin provides the epigenetic and structural foundation to assemble the kinetochore, recruiting inner kinetochore 
proteins CENP-B, CENP-C, and CENP-N (Régnier et al, 2005; Mendiburo et al, 2011).

Together, these inner kinetochore components provide recognition motifs for outer kinetochore proteins in the conserved KMN network (KLN1, MIS12 and NDC80 complexes (Cheeseman et al, 2006; Przewloka et al, 2007; DeLuca \& Musacchio, 2012; Weir et al, 2016). Deleting either CENP-A or CENP-C results in cell death or senescence (Fukagawa et al, 1999; Kwon et al, 2007; McKinley \& Cheeseman, 2016), but this happens only after a few cell cycles. These data indicate that both CENP-A and CENP-C are often present in excess for what is required to form a functional kinetochore for one cell cycle. Furthermore, CENP-A and CENP-C are long lived proteins guaranteeing faithful chromosome segregation even after their respective genes have been deleted (Kalitsis et al, 1998; Howman et al, 2000; Suzuki et al, 2011; Bodor et al, 2013; Smoak et al, 2016).

Despite major advances made in understanding the hierarchy of the centromere and kinetochore proteins (McKinley \& Cheeseman, 2016; Milks et al, 2009; Cheeseman, 2014; Klare et al, 2015), little is known about the physical features of the inner kinetochore bound to centromeric chromatin in multicellular eukaryotes. Individual mitotic kinetochores were isolated from budding yeast by using a FLAG-tagged outer kinetochore component Dsn1 as bait (Gonen et al, 2012). Point centromeres of budding yeast are unique because they display a one-to-one correspondence, in which a single CENP-A containing nucleosome (Bloom \& Carbon, 1982; Saunders et al, 1988; Furuyama \& Henikoff, 2009; Kingston et al, 2011; Krassovsky et al, 2012; Furuyama et al, 2013; Henikoff et al, 2014; Díaz-Ingelmo et al, 2015) binds to a single microtubule via the kinetochore. In contrast, the human centromeres are regional centromeres comprised of megabase-sized $\alpha$-satellite arrays (Waye \& Willard, 1989; Rudd et al, 2005). 
Recent advances in super resolution microscopy suggest that each human centromere harbors 400 CENP-A molecules (Bodor et al, 2014), which eventually associate with only $\sim 17$ mitotic microtubule spindles (Suzuki et al, 2015). This inner kinetochore chromatin is thought to be folded into a boustrophedon (Ribeiro et al, 2010; Vargiu et al, 2017), in which the number of CENP-A nucleosomes present appears to exceed the number needed for centromere function. In recent work, we reported that CENP-A nucleosomes alone are twice as elastic as H3 nucleosomes, and that CENP-C fragments can suppress and rigidify CENP-A motions, correlating with increased compaction of the centromeric chromatin fiber in vitro and in vivo. (Melters et al, 2019) Here, we wished to provide deeper insights into kinetochore bound CENPA chromatin in human cells.

Using nanoscale, immunofluorescence imaging, and biochemical approaches, we report that we were able to purify at least two classes of CENP-A chromatin populations in human cells. One class of CENP-A nucleosomes was weakly associated with inner kinetochore proteins and possesses diminutive dimensions; whereas a second class of CENP-A nucleosomes co-elute and co-purify with inner kinetochore proteins and display stabilized configurations. Interestingly, overexpression of CENP-C alters the balance of these two CENP-A classes, resulting in overall reduced RNA polymerase 2 occupancy, reduced de novo loading of CENP-A nucleosomes, and extensive mitotic defects. CENP-A mutants that either serve as a sink for excess CENP-C or which are unable to bind CENP-C rescue these mitotic defects. Altogether, these data support a working model in which the balance between CENP-A and kinetochore components is critical for centromere homeostasis. 


\section{Results}

\section{Two classes of centromeric chromatin can be purified from human centromeres}

In previous work, we purified human CENP-A nucleosomes under a range of conditions, and analyzed them by various biochemical, EM and AFM approaches (Dimitriadis et al, 2010; Bui et al, 2012). We occasionally noticed a small fraction of macromolecular complexes within CENPA native chromatin-immunoprecipitation (N-ChIP), that were large, compacted, and refractory to standard nucleosome analysis (Dimitriadis et al, 2010; Bui et al, 2012). We were curious to examine these larger complexes. Therefore, we developed a gentle, native, serial chromatinimmunoprecipitation assay to purify CENP-C bound chromatin from HeLa cells (Supplemental Figure S1). We mildly digested nuclear chromatin with micrococcal nuclease (MNase), and performed N-ChIP by first pulling-down CENP-C bound chromatin and subsequent pullingdown any remaining CENP-A chromatin using ACA serum (Earnshaw \& Rothfield, 1985) (Figure 1A).

We used quantitative immunoblotting to quantify the relative abundance of native CENP-A bound to CENP-C (Figure 1B) and free CENP-A chromatin. The enrichment of the N-ChIP'ed samples was measured over the input. We observed a 2.0 \pm 0.8 -fold enrichment of CENP-A in the CENP-C N-ChIP and an 8.5 \pm 2.8 -fold enrichment of CENP-A in the serial ACA N-ChIP (Figure 1C). Thus, our results indicate that in HeLa cells, there is a $\sim 4$.7-fold excess of CENP-A that is weakly or not associated with CENP-C.

We wanted to test the possibility that during the experimental procedure of N-ChIP, weakly bound CENP-C could dissociate from CENP-A chromatin, we cross-linked samples prior to 
ChIP. Although in our hands overall chromatin extraction efficiency is generally lower under XChIP conditions, we still observed a 2.5 \pm 0.9 -fold enrichment of CENP-A in the CENP-C XChIP and a 7.5 \pm 3.7 -fold enrichment of CENP-A in the ACA X-ChIP (Figure 1C, Supplemental Figure S1E, Table S1).

We next tested the possibility that CENP-C may be dissociating from one class of CENP-A chromatin, in which case it would accumulate in the nuclear pellet. To examine how much CENP-C is lost during purification, we loaded a gradient of nuclear extract in addition to the serial N-ChIP (Figure 1D). We observed that very little CENP-C remained in the nuclear debris/pellet. These data lend confidence to the interpretation that the majority of CENP-C was pulled-down in the CENP-C N-ChIP.

Next, we tested whether the two types of CENP-A populations have similar sedimentation patterns. Following MNase digestion, we ran the chromatin on a 5-20\% glycerol gradient and performed serial N-ChIP on both every fraction (Supplemental Figure S2A). Whereas the free CENP-A population had a sedimentation pattern very similar to input chromatin, CENP-C associated CENP-A chromatin showed a distinctively different sedimentation pattern (Supplemental Figure S2). The relative abundance of longer chromatin arrays in the CENP-C NChIP was also observed by high resolution capillary electrophoresis (BioAnalyzer, Supplemental Figure S3). We were curious to test whether CENP-C-associated chromatin occupied unique centromeric sequences compared to CENP-C-depleted CENP-A chromatin. In order to test this possibility, we performed ChIP-seq replicates, and analyzed the DNA sequences against the 
several centromeric references. These analyses showed that both CENP-A populations occupy similar centromeric sequences (Supplemental Figure S4).

Altogether, these data suggest that there is a sizeable fraction of CENP-A chromatin which is weakly associated with CENP-C, and a smaller fraction of CENP-A which is very robustly bound to CENP-C.

\section{CENP-A nucleosomes robustly bound to CENP-C co-purify with other CCAN components}

The chromatin we extracted is from cycling HeLa cells, the majority of which are in G1 phase (Pettersen et al, 1977). Throughout the cell cycle the constitutive centromere associated network (CCAN) complex, which is composed of several proteins, is bound to the centromeric chromatin to form the inner kinetochore (Figure 2A) (Pesenti et al, 2016; McKinley \& Cheeseman, 2016). To test whether other components of the CCAN are present within the complex within CENPA:CENP-C above, we performed western blot analyses on these purified CENP-C complexes. In addition to CENP-A, H2A, and H2B, CCAN components CENP-B, CENP-I, CENP-N, CENPW, and CENP-T were enriched (Figure 2B). To our surprise, the dedicated chaperone for CENPA assembly, HJURP was also enriched in the CENP-C N-ChIP. This result supports a recent report from novel BioID experiments, which show that HJURP is associated with CENP-A chromatin at multiple points of the cell cycle (Remnant et al, 2019). Overall, our purified CENPA:CENP-C complex robustly represents the CCAN. Furthermore, outer kinetochore components MIS12 and HEC1/NDC80 were modestly enriched in the CENP-C N-ChIP (Figure 2B).

Altogether, from these data, we deduced that the large CENP-C complex that was enriched in 
fraction 12 of our glycerol gradient experiments (Supplemental Figure S2D) includes the full CCAN, possibly representing fully matured kinetochores.

\section{Inner kinetochore associated chromatin is not uniquely enriched in histone $\mathrm{H} 2 \mathrm{~A}$ variants}

Heterotypic CENP-A/H3.3 nucleosomes have been reported, but they are generally restricted to ectopic sites (Athwal et al, 2015; Nye et al, 2018; Lacoste et al, 2014). Where histone H3 and H2B have few variants, there are several histone H2A variants including macroH2A, H2A.Z, and $\gamma \mathrm{H} 2 \mathrm{~A} . \mathrm{X}$ (Melters et al, 2015). Indeed, mass-spectrometry data has suggested that H2A histone variants might form nucleosomes with CENP-A (Foltz et al, 2006; Bailey et al, 2016). We therefore set out to interrogate the possibility that CENP-A nucleosomes associated with the inner kinetochore contained other histone variants. As before, we performed a CENP-C N-ChIP followed by a serial ACA N-ChIP and tested both samples for the presence of histone H2A variants. Interestingly, while we detected H2A.Z and macroH2A variants in both CENP-C and ACA N-ChIP (Figure 2C), their relative abundance was not quantifiably different between the two CENP-A populations (Figure 2D, Supplemental Table S2). Consequently, while these data do not currently yield evidence that $\mathrm{H} 2 \mathrm{~A}$ variants might contribute to structural differences between the two CENP-A populations, they do support previous data (Foltz et al,. 2006; Bailey et al., 2016), suggesting that $\mathrm{H} 2 \mathrm{~A}$ variants can incorporate into centromeric chromatin, albeit by mechanisms yet unknown.

\section{Development of immuno-AFM to verify the identity of nucleosomes associated with the CENP-C complex}


The purification of CENP-A chromatin bound to the full CCAN from human cells presents an exciting opportunity to study this complex in its native form. In order to do this robustly, we needed a method to confirm the identity of nucleosomes associated with CENP-C, complementary to the Western blot analyses provided above (Figures 1, S2). To this end, we developed a single-molecule based method to test whether CENP-A nucleosomes are physically present in CENP-C N-ChIP samples. Inspired by classical immuno-EM protocols (e.g.

Dimitriadis et al, 2010), and recognition-AFM (e.g. Wang et al., 2008), in which we have shown we can confirm the identity of histones in a purified biological sample, we adapted immunolabeling for in-air atomic force microscopy (AFM) (Figure 3A).

We first visualized samples by AFM either without antibody; or, primary $\left(1^{\circ}\right)$ mouse monoclonal anti-CENP-A antibody; or, $1^{\circ}$ CENP-A antibody and, either secondary $\left(2^{\circ}\right)$ anti-mouse antibody or $2^{\circ}$ anti-mouse Fab fragment. The $1^{\circ}$ antibody by itself was $0.8 \pm 0.2 \mathrm{~nm}$ in height and the addition of the $2^{\circ}$ antibody resulted in a height increase to $2.0 \pm 0.5 \mathrm{~nm}$ (Figures $3 \mathrm{~B}, \mathrm{C}$, Supplemental Table S3, Raw Data File 1). To confirm the $1^{\circ}$ antibody's specificity, we used in vitro reconstituted recombinant $\mathrm{H} 3$ or CENP-A nucleosomes as before and incubated them with either no antibody (no $\mathrm{Ab}$ ); $1^{\circ}$ alone, or $1^{\circ}+2^{\circ}$ antibodies, respectively (Figures $3 \mathrm{~B}, \mathrm{C}$ ). As expected, control in vitro reconstituted $\mathrm{H} 3$ nucleosomes did not show a shift in particle height in the presence of anti-CENP-A antibodies (no Ab: $2.2 \pm 0.2 \mathrm{~nm}, 1^{\circ}: 2.1 \pm 0.2 \mathrm{~nm}$, and $2^{\circ}: 2.2 \pm 0.1 \mathrm{~nm}$, resp.). However, in vitro reconstituted CENP-A nucleosomes did increase in height upon binding to their antibodies (no Ab: $2.2 \pm 0.2 \mathrm{~nm}, 1^{\circ}: 2.5 \pm 0.3 \mathrm{~nm}$, and $4.6 \pm 1.4 \mathrm{~nm}$ with $2^{\circ}$ antibody, or 3.2 $\pm 0.6 \mathrm{~nm}$ with Fab fragment, resp., Figures 3B, C, S5, Supplemental Table S3, Raw Data File $1)$. 
Having standardized this approach on in vitro reconstituted samples, we next applied this method to in vivo samples, namely native $\mathrm{H} 3$ or CENP-C purified chromatin (Figures 3B, C). Similar to reconstituted $\mathrm{H} 3$ nucleosomes, native bulk $\mathrm{H} 3$ chromatin did not demonstrate a shift in particle height when incubated with anti-CENP-A antibodies (no Ab: $2.3 \pm 0.2 \mathrm{~nm}, 1^{\circ}: 2.4 \pm 0.3 \mathrm{~nm}$, and $2^{\circ}: 2.3 \pm 0.1 \mathrm{~nm}$, resp.). In contrast, nucleosomal particles that came down in the CENP-C N-ChIP displayed a shift in height when challenged with anti-CENP-A antibodies (no Ab: $2.4 \pm 0.4 \mathrm{~nm}$, $1^{\mathrm{o}}: 2.6 \pm 0.4 \mathrm{~nm}$, and $2^{\mathrm{o}}: 3.9 \pm 1.3 \mathrm{~nm}$, resp.). These results support biochemical evidence based on Western blots, that CENP-A nucleosomes are indeed associated with the purified CENP-C complex in these purified complexes.

\section{Physically altered CENP-A nucleosomes are bound to the inner kinetochore}

We next sought to analyze physical characteristics of purified CCAN associated CENP-A chromatin in its native context. This, to our knowledge, has not been accomplished before from native human centromeres. We split the samples in half and imaged the same samples independently (by two different operators) using two complementary high resolution singlemolecule methods: in-air AFM, and transmission electron microscopy (TEM) (Figures 4A, B, S6). To retain integrity of the chromatin, samples were analyzed within 24 hours of purification. By AFM and by TEM, we observed several similar features. First, we observe large polygonal structures with a roughly circular footprint (height: $5.8 \pm 2.1 \mathrm{~nm}$; area: $629 \pm 358 \mathrm{~nm}^{2}$ ), generally associated with four to six nucleosomes (Figures 4A, B, S6, Table S4, Raw Data File 2). Compared to individual CENP-A nucleosomes, these complexes were substantially larger. As important controls, we analyzed control mock IPs, bulk chromatin, or CENP-A N-ChIP (Figures 
4A, B, S6), which did not display these polygonal complexes. Together, this suggests these structures arise specifically from the CENP-C/CCAN bound complex. Interestingly, by AFM, we observed that the largest of CENP-C complexes tends to be associated with a $\sim 230 \mathrm{bp}$ long nucleosome-free DNA (Figure 4A, Table S4, Raw Data File 2). The same samples, analyzed in parallel by TEM, displayed similar features (Figure 4B), including the association of four to six nucleosomes at the periphery of the complex.

We next turned our attention to individual nucleosomes associated with the CENP-C complex. In our previous work, in vitro reconstituted recombinant octameric CENP-A nucleosomes on 601 or $\alpha$-satellite DNA behave similar to H3 when measured by in-air AFM, with average heights of $\sim 2.4 \mathrm{~nm}$ and widths of $\sim 12 \mathrm{~nm}$ (Athwal et al, 2015; Walkiewicz et al, 2014b). This observation is consistent with measurements made by static biophysical, EM, and crystallographic methods, which generally show that except for flexible exit/entry DNA termini and loop 1, in vitro reconstituted CENP-A nucleosomes have dimensions similar to $\mathrm{H} 3$ nucleosomes (Tachiwana et al, 2011; Walkiewicz et al, 2014b; Roulland et al, 2016; Kim et al, 2016; Vlijm et al, 2017).

In contrast, native CENP-A nucleosomes purified from either fruit fly or human cell lines generally display smaller dimensions compared to native $\mathrm{H} 3$ nucleosomes, except during S phase (Athwal et al, 2015; Bui et al, 2012; Dimitriadis et al, 2010; Dalal et al, 2007; Bui et al, 2013). Indeed, we recapitulated these observations here. Relative to $\mathrm{H} 3$ nucleosomes $(2.5 \pm 0.3 \mathrm{~nm})$

(Figure 4C, Table S5, Raw Data File 3), native bulk CENP-A nucleosomes not associated with CENP-C are continuing to be uniquely identifiable by their smaller average height of $1.9 \pm 0.3 \mathrm{~nm}$ (Figure 4C). 
We examined CENP-A nucleosomes that are physically associated with the CENP-C complexes

(Figure 4C, Table S5, Raw Data File 3). CENP-A nucleosomes associated with CENP-C complexes had distinctly larger dimensions, with a height of $2.4 \pm 0.5 \mathrm{~nm}$ (Figure 4C), significantly taller than bulk CENP-A nucleosomes alone (two-sided t-test $\mathrm{p}<0.001$ ).

These results point to the presence of two physically distinct CENP-A nucleosomes within the human centromere: one species of CENP-A nucleosome which is shorter, and another species of CENP-A nucleosome associated with the CENP-C/CCAN complex (Figure 4D), which adopts a taller configuration.

\section{CENP-C overexpression does not lead to increased DNA breaks}

Cumulatively, the data above suggest that one type of structure in the inner kinetochore is comprised of a polygonal dome-like structure with a roughly circular footprint, associated with a chromatin sub-domain comprised of four to six octameric CENP-A nucleosomes. Yet another type of domain in the centromere contains smaller CENP-A nucleosomes. Chromatin fiber studies show that CENP-A and H3 chromatin domains are interspersed (Sullivan \& Karpen, 2004; Blower et al, 2002; Ribeiro et al, 2010; Kyriacou \& Heun, 2018). Indeed, recent work show that CENP-C and CENP-A do not perfectly overlap on chromatin fibers (Padeganeh et al, 2013; Kyriacou \& Heun, 2018). Recent structural studies of CENP-A nucleosome suggest that CENP-A nucleosome are innately more flexible compared to H3 nucleosomes (Winogradoff et al., 2015; Falk et al., 2016; Roulland et al., 2016; Malik et al., 2018; Melters et al., 2019 in press), whereas CENP-C strongly suppresses CENP-A nucleosomes motions (Falk et al., 2015, 
2016; Melters et al., 2019 in press). This raises an intriguing question on potential roles for maintaining unbound or free CENP-A centromeric chromatin in vivo.

A plausible and attractive hypothesis is that during mitosis, flexible CENP-A particles might provide a mechanical "bungee"-like state, which allows the dissipation of mitotic forces. In this scenario, excess CENP-C would be predicted to dampen the motions of CENP-A nucleosomes, thereby reducing the overall springiness of centromeric chromatin. Thus, loss of the flexible CENP-A domain might result in an accumulation of DNA breaks during mitosis. To test this hypothesis, we overexpressed C-terminally tagged GFP CENP-C $\left(\mathrm{CENP}-\mathrm{C}^{\mathrm{OE}}\right)$ for three days, in cells synchronized to late mitosis and early G1 and scored for the DNA break marker $\gamma \mathrm{H} 2 \mathrm{~A} . \mathrm{X}$. Although we found an increase in mitotic defects, no appreciable increase in $\gamma \mathrm{H} 2 \mathrm{~A} . \mathrm{X}$ foci was observed at centromeric foci (Figure 5). These data suggest that partial reduction in the amount of free CENP-A does correlate with mitotic defects, a priori it does not appear to cause an increase in DNA breaks. We were curious why these mitotic defects arose and considered alternative hypotheses that might explain the result.

\section{CENP-C overexpression limits de novo CENP-A loading}

An obvious second hypothesis arises from decades of data in the transcription field, which suggests that chromatin that is more "open" or accessible, is more likely to be transcriptionally permissive (Maeshima et al, 2019; Klemm et al, 2019). Thus, we speculated that free CENP-A chromatin might be necessary for centromeric transcription. RNA polymerase 2 (RNAP2) mediated centromeric transcription has been shown to be critical for de novo CENP-A loading in multiple species (reviewed in Müller and Almouzni, 2017). In parallel work, we have observed 
that overexpression of CENP-C results in reduced RNAP2 levels at centromeric chromatin (Melters et al., 2019 in press). Therefore, a logical prediction is that limiting access of the transcriptional machinery to CENP-A chromatin (Figures 6A, B), should reduce new CENP-A loading. An initial clue supporting this possibility was deduced from western blot analysis, in which over-expression of CENP-C led to a significant reduction in the free CENP-A population (two-sided t-test $p<0.05$; Figure 6B, Table S6). To test whether CENP-C ${ }^{\mathrm{OE}}$ would specifically lead to a reduction in new CENP-A loading, we turned to the well-established SNAP-tagged CENP-A system combined with quench pulse-chase immunofluorescence (Bodor et al, 2012). Using this system in cells synchronized to mid-G1, one can distinguish between older CENP-A (TMR-block) and newly incorporated CENP-A (TMR-Star) (Figures 6C, D). Strikingly, in the CENP-C overexpression background, in which we observed RNAP2 is depleted from centromeric chromatin in early G1 (Figure 6A, B), we concomitantly observed a 2.3-fold reduction of de novo incorporation of CENP-A (two-sided t-test $p<0.00001$; Figures 6E, F, Raw

Data File 4). Therefore, in vivo CENP-C ${ }^{\mathrm{OE}}$ leads to suppression of RNAP2 occupancy, reduction in total free CENP-A levels (Figures 6A, B), and a reduction in de novo CENP-A loading (Figures 6E, F).

\section{CENP-A mutants rescue mitotic defects caused by CENP-C overexpression}

As has been reported previously in chicken DT-40 cells (Fukagawa et al, 1999), we observed that overexpressing CENP-C resulted in a quantifiable increase in mitotic defects (40\% normal, $60 \%$ abnormal) relative to wildtype cells (74\% normal, 36\% abnormal), most notably lagging chromosomes and multipolar spindles (Figure 7A, B). 
CENP-C functionally docks at the C-terminal tail of CENP-A nucleosomes (Carroll et al, 2010; Falk et al, 2016, 2015; Kato et al, 2013; Guo et al, 2017; Ali-Ahmad et al, 2019). We reasoned that expressing CENP-A mutants which can either sequester away excess CENP-C, or which are insensitive to CENP-C, should rescue the defects noted above. Therefore, in the background of CENP-C over-expression, we expressed either a fusion of H3 with the C-terminal tail of CENPA $\left(\mathrm{H}^{\mathrm{CpA}}{ }^{\mathrm{CTD}}\right)$ which can bind CENP-C, or CENP-A lacking its C-terminal tail (CENP-A $\left.{ }^{\triangle \mathrm{CTD}}\right)$ which can still be deposited to centromeres by the chaperone HJURP, but which cannot bind CENP-C (Figure 7A).

In the background of CENP-C overexpression, $\mathrm{H} 3^{\mathrm{CpA} C \mathrm{CTD}}$ should function as a sink for excess CENP-C. In contrast, CENP-A ${ }^{\triangle \mathrm{CTD}}$ should reintroduce a free CENP-A population. Indeed, upon scoring mitotic cells in the background of overexpressing CENP-C and the two mutants, we observed that multipolar spindle defects were rescued by both $\mathrm{H} 3^{\mathrm{CpA}} \mathrm{CTD}$ ( $58 \%$ normal, $42 \%$ abnormal), and CENP-A ${ }^{\triangle \mathrm{CTD}}(65 \%$ normal, 35\% abnormal) (Figure $7 \mathrm{~B})$.

Together, these data show that CENP-C overexpression reduces RNAP2 occupancy at the centromeric chromatin, reduces free CENP-A levels (Figures 6A, B), and reduces incorporation of de novo CENP-A (Figure 6E, F), and results in an increase in mitotic defects (Figure 7B). Reintroducing either a free CENP-A population or a $3^{\mathrm{CpA} C \mathrm{CTD}}$ sink results in a rescue of mitotic defects (Figure 7B). These data suggest a working model where a balance between kinetochore bound and free CENP-A chromatin is important for centromere homeostasis. 


\section{Discussion}

Since the discovery of CENP-A (Earnshaw \& Rothfield, 1985; Palmer et al, 1991), it has been demonstrated that CENP-A nucleosomes are required and sufficient to form kinetochores (Régnier et al, 2005; Mendiburo et al, 2011). At the same time, it is puzzling that more CENP-A nucleosomes reside at the centromere than are strictly needed to successfully seed a kinetochore (McKinley \& Cheeseman, 2016; Bodor et al, 2013). Indeed, while our current study was under revision, a recent chromatin fiber study employed a proximity based labeling technique called BioID, finding that CENP-A foci do not entirely overlap with CENP-C foci (Kyriacou \& Heun, 2018). Our data strongly supports and extends this finding using a completely independent approach.

We report on the existence of two classes CENP-A nucleosomes in vivo. One class of CENP-A nucleosomes was strongly associated with the CENP-C complex, along with other components of the inner kinetochore/CCAN; whereas another population of CENP-A nucleosomes is weakly associated with CENP-C. Strikingly CENP-A nucleosomes associated with the CENP-C complex have altered dimensions relative to bulk CENP-A nucleosomes alone (Figure 4D). Allatom computational modeling has previously indicated that CENP-A nucleosomes have a weaker four helix bundle resulting in an intrinsically more disordered nucleosome core compared to a canonical H3 nucleosome (Winogradoff et al, 2015), that this flexibility arises from the CENPA/H4 dimer (Zhao et al, 2016), is lost in the tetramer (Zhao et al, 2019) but regained in the CENP-A octamer, resulting in an energetically "frustrated" nucleosome, which predicts the existence of multiple deformation states of CENP-A (Winogradoff et al., 2015; Bui et al., 2012). These data also predict that kinetochore components especially CENP-C could fix one preferred 
conformational state. Indeed, previous in vitro work has shown that both the central domain and the conserved CENP-C motif make contact with the CENP-A C-terminal tail and $\mathrm{H} 2 \mathrm{~A}$ acidic patch (Kato et al, 2013). In hydrogen-deuterium exchange and smFRET experiments of in vitro reconstituted CENP-A mononucleosomes, these contacts result in changes in the overall shape of CENP-A nucleosome by bringing the two nucleosome halves closer together and limiting the DNA sliding (Falk et al, 2015, 2016; Guo et al, 2017). As a result, the CENP-A nucleosome when bound to the central domain of CENP-C has an appearance similar to a canonical H3 nucleosome, a result we recently demonstrated using computational, nanobiophysical and biochemical tools (Melters et al, 2019). Indeed, in the CENP-C purified samples from human centromeres, we observe a shift in nucleosomal height when CENP-A nucleosomes associate with CENP-C complexes. One interpretation of this shift is that the CENP-C complex stabilizes the octameric conformation of the CENP-A nucleosome in vivo. We note that other interpretations are equally plausible: for example, the binding of kinetochore partners may alter the physical dimensions of nucleosomes in the complex; or, the absence or presence of DNA/histone modifications might limit the conformational space that can be sampled on minute time scales by CENP-A nucleosomes (Winogradoff et al, 2015; Bui et al, 2017; Stumme-Diers et al, 2018).

Interestingly, overexpression of CENP-C in HeLa cells induced a 6-fold increase in multipolar spindles and 2-fold increase in lagging chromosome (Figure 7). A correlation between multipolar spindles and merotelic chromosome attachment was described (Silkworth et al, 2009). Merotelic attachment are a common feature of cancer cells and are believed to be a driving force of chromosome instability (CIN) (Salmon et al, 2005; Gregan et al, 2011). Interestingly, both the 
multipolar and the lagging chromosome phenotype we observed were rescued by re-establishing a balance between the two CENP-A domains (Figure 7). This raises the possibility that multipolar spindles can be directly regulated by either the kinetochore or possibly even CENP-C. Several important questions arise from this observation; first, does overexpression of CENP-C create a platform which might allow a larger kinetochore to be formed, thereby promoting merotelic attachments; second, does free CENP-A chromatin provide cues to direct the kinetochore to face the spindle poles, either by organizing centromeric chromatin and/or by regulating inner centromere proteins localization, like Aurora B? These will be interesting questions to pursue in follow-up work.

We observed that overexpression of CENP-C also reduced the level of de novo incorporation of CENP-A nucleosomes (Figure 6E, F). Previous work has shown that CENP-A incorporation is dependent on centromeric transcription (reviewed in Müller and Almouzni, 2017). Indeed, levels of centromeric RNAP2 were reduced in early G1 (Figure 6B), providing further evidence that nucleosome loading requires polymerase activity. Furthermore, recent work showed that nucleosome binding partners have the capacity to alter nucleosome's innate distortability (Falk et al, 2016, 2015; Sanulli et al, 2019), as well as compact chromatin (Melters et al, 2019; Sanulli et al, 2019). Altogether, this points to the intriguing possibility that CENP-C overexpression alters centromeric chromatin is such a way that it becomes less accessible to the transcriptional machinery. This fraction of chromatin is in juxtaposition to free CENP-A chromatin, which is unable to be bound and suppressed by linker histone H1 (Roulland et al, 2016), combined with the intrinsic distortability of CENP-A nucleosomes might (Winogradoff et al., 2015; Malik et al., 2018), we think, create an innate open chromatin state, readily accessible to specific transcription 
associated factors. Nevertheless, there are some caveats which present a puzzle for which we have not arrived at satisfying answers yet. In wild-type conditions we observed RNAP2 to be present in both CENP-A populations. This raises the question, if CENP-C associated CENP-A chromatin is less accessible, how did RNAP2 get there? One feasible answer is that the entry and exit DNA strands of CENP-C associated CENP-A nucleosomes are as accessible as in unbound CENP-A nucleosomes; but access to the DNA wrapped by the CENP-A nucleosome is impaired upon CENP-C binding. To load RNAP2 to the chromatin fiber, the pre-initiation complex (PIC) has to be formed first. Thus, an important current problem is to identify where the PIC forms- at the free CENP-A chromatin, or on the bordering H3K4me2 containing domains mapped within the centromere over two decades ago, the function of which still remains mysterious (Sullivan \& Karpen, 2004).

In summary, in this report we describe that CENP-A nucleosomes display two alternative conformational states in vivo, both of which are important for centromere fidelity in cycling cells. Nucleosome dynamics play an important role in genome compaction, protection from DNA damaging agents, and regulating DNA access by DNA binding factors. These dynamics are driven by only a few interactions between the interfaces of DNA and nucleosomes (Polach \& Widom, 1995; Widom, 1998; Fierz \& Poirier, 2019). Recently, we described a CENP-A core post-translation modification (PTM) that altered the binding of CENP-C to CENP-A in vivo (Bui et al, 2017). An exciting line of future investigation is to examine how DNA or histone modifications which promote specific conformations of CENP-A nucleosomes, might alter its interactions with chaperones, kinetochore partners, and its occupancy on centromere $\alpha$-satellite DNA. It will also be of interest to investigate whether nucleosome stabilizing or destabilizing 
interactions promote or suppress centromeric transcription required for the epigenetic memory of centromeres in various species (Wong et al, 2007; Chueh et al, 2009; Li et al, 2008; Ferri et al, 2009; Bergmann et al, 2011; Choi et al, 2011; Ohkuni \& Kitagawa, 2011; Quénet \& Dalal, 2014; Rošić et al, 2014; Catania et al, 2015; Bobkov et al, 2018; McNulty et al, 2017; Zhu et al, 2018; Ling \& Yuen, 2019; Grenfell et al, 2016; Chan \& Wong, 2012; Melters et al, 2019 in press), and for chaperone interactions required for correct targeting of CENP-A, which we, and others, have demonstrated is defective in cancer cells (Athwal et al, 2015; Zhao et al, 2016; Nye et al, 2018).

\section{Material and Methods}

Key Resources Table

\begin{tabular}{|l|l|l|l|l|}
\hline Reagents or Resource & Source & Identifier & Application & Quantity \\
\hline ACA serum & BBI Solutions & SG140-2 & N-ChIP, X-ChIP & $5 \mu \mathrm{L}$ \\
\hline Anti-CENP-A (rabbit) & Custom made & & N-ChIP & $3 \mu \mathrm{L}$ \\
\hline Anti-CENP-A (mouse) & Abcam & ab13939 & IF & $1: 1000$ \\
\hline Anti-CENP-A (rabbit) & Abcam & ab45694 & WB & $1: 3000$ \\
\hline Anti-CENP-A (rabbit) & Milipore & $04-205$ & WB & $1: 3000$ \\
\hline Anti-CENP-B (rabbit) & Santa Cruz & sc-22788 & WB & $1: 500$ \\
\hline Anti-CENP-C (guinea pig) & MBL International & PD030 & N-ChIP, X-ChIP, & $5 \mu \mathrm{L}$ \\
& & & IF & $1: 1000$ \\
\hline Anti-CENP-C (rabbit) & Santa Cruz & sc-22789 & WB & $1: 500$ \\
\hline Anti-CENP-N & Avivasysbio & ARP57258-P050 & WB & $1: 500$ \\
\hline Anti-CENP-I & Bethyl & A303-374A & WB & $1: 1000$ \\
\hline Anti-CENP-T & Bethyl & A302-314A & WB & $1: 1000$ \\
\hline Anti-CENP-W & Invitrogen & PA5-34441 & WB & $1: 300$ \\
\hline Anti-MIS12 & Abcam & ab70843 & WB & $1: 500$ \\
\hline Anti-HEC1/NDC80 & GeneTex & GTX70268 & WB & $1: 1000$ \\
\hline Anti-macroH2A.1 & Abcam & ab37264 & WB & $1: 1000$ \\
\hline Anti- $\gamma$ H2A.X & Abcam & ab11174 & IF & $1: 1000$ \\
\hline Anti- $\gamma$ H2A.X & Abcam & ab2893 & WB & $1: 1000$ \\
\hline Anti-H2A.Z & Abcam & ab4179 & WB & $1: 1000$ \\
\hline Anti-H2A & Abcam & ab18255 & WB & $1: 1000$ \\
\hline Anti-H2B & Abcam & ab1790 & WB & $1: 1000$ \\
\hline Anti-H4 & Cell Signaling & $2935 T$ & WB & $1: 1000$ \\
\hline Anti-H3 & Santa Cruz & sc-8654 & WB & $1: 3000$ \\
\hline
\end{tabular}

\section{Software and Algorithms Software and Algorithms}

\begin{tabular}{|l|l|l|}
\hline RepBase & & hhtp://www.girinst.org/repbase \\
\hline Gwyddion & & http://gwyddion.net/ \\
\hline
\end{tabular}




\begin{tabular}{|l|l|l|}
\hline $\mathrm{R}$ & & https://www.r-project.org/ \\
\hline NIH ImageJ & & https://imagej.nih.gov/ij/ \\
\hline Bio-Formats & & https://www.openmicroscopy.org/bio-formats/ \\
\hline CRaQ & & http://facilities.igc.gulbenkian.pt/microscopy/microscopy-macros.php \\
\hline
\end{tabular}

Native and cross-linked Chromatin-Immunoprecipitation and Western blotting

Human cell line HeLa were grown in DMEM (Invitrogen/ThermoFisher Cat \#11965)

supplemented with 10\% FBS and 1X penicillin and streptomycin cocktail. N-ChIP experiments were performed without fixation. After cells were grown to $\sim 80 \%$ confluency, they were harvested as described (Bui et al, 2012, 2017). For best results for chromatin preparation for AFM the pellet that is obtained after each spin-down during the nuclei extraction protocol (Walkiewicz et al, 2014a) is broken up with a single gentle tap. Nuclei were digested for 6 minutes with 0.25 U MNase/mL (Sigma-Aldrich cat \#N3755-500UN) and supplemented with $1.5 \mathrm{mM} \mathrm{CaCl}_{2}$. Following quenching (10 mM EGTA), nuclei pellets were spun down, and chromatin was extracted gently, overnight in an end-over-end rotator, in low salt solution $(0.5 \mathrm{X}$ PBS; 0.1 mM EGTA; protease inhibitor cocktail (Roche cat \#05056489001). N-ChIP chromatin bound to Protein G Sepharose beads (GE Healthcare cat \#17-0618-02) were gently washed twice with ice cold $0.5 \mathrm{X}$ PBS and spun down for 1 minute at $4^{\circ} \mathrm{C}$ at $800 \mathrm{rpm}$. Following the first $\mathrm{N}-$ ChIP, the unbound fraction was used for the sequential N-ChIP. X-ChIP experiments were performed with fixation (Skene \& Henikoff, 2015). Westerns analyses were done using LiCor's Odyssey CLx scanner and Image Studio v2.0.

\section{Glycerol gradient sedimentation}

A total of $2 \mathrm{~mL}$ of extracted chromatin was applied to $10 \mathrm{~mL}$ of 5 to $20 \%$ glycerol gradient containing $50 \mathrm{mM}$ Tris-HCl pH 8.0, 2 mM EDTA, 0.1\% NP-40, 2 mM DTT, $0.15 \mathrm{M} \mathrm{NaCl}$, and 
$1 \mathrm{X}$ protease inhibitor cocktail layered over $0.4 \mathrm{~mL}$ of $50 \%$ glycerol. The chromatin was centrifuged with a SW41Ti rotor (Beckman) at 22,000 rpm for 15.5 hours at $4^{\circ} \mathrm{C} .1 \mathrm{~mL}$ aliquots were fractioned from the top, and DNA and protein samples were separated by either $1.2 \%$ agarose gel electrophoreses or 4-20\% SDS-PAGE gels, respectively. Serial N-ChIP was performed on all 12 fractions.

\section{AFM and image analysis}

Imaging of CENP-C and CENP-A N-ChIP and bulk chromatin was performed as described (Dimitriadis et al, 2010; Walkiewicz et al, 2014a) with the following modifications. Imaging was performed by using standard AFM equipment (Oxford Instruments, Asylum Research's Cypher S AFM, Santa Barbara, CA) with silicon cantilevers (OTESPA or OTESPA-R3 with nominal resonances of $\sim 300 \mathrm{kHz}$, stiffness of $\sim 42 \mathrm{~N} / \mathrm{m}$, and tip radii of 3-7 nm) in noncontact tapping mode. $10 \mu \mathrm{l}$ of bulk, CENP-A, or CENP-C chromatin sample was deposited on APS-treated mica (Dimitriadis et al, 2010; Walkiewicz et al, 2014a). The samples were incubated for $10 \mathrm{~min}$, rinsed gently to remove salts, and dried mildly under vacuum before imaging. Automated image analysis was performed as described in (Walkiewicz et al, 2014a) with the only modifications that R software was used instead of Microsoft Excel. A total of six biological replicates were performed for CENP-C experiments and three biological replicates for both the CENP-A and bulk chromatin experiments. Bulk chromatin from the same preparation was imaged in parallel to get the baseline octameric range. For all samples, manual spot analyses were performed to confirm accuracy of automated analyses.

\section{Immuno- $A F M$}


In vitro reconstitution of CENP-A (CENP-A/H4 cat\#16-010 and $\mathrm{H} 2 \mathrm{~A} / \mathrm{H} 2 \mathrm{~B}$ cat\#15-0311, EpiCypher, Research Triangle Park, NC) and H3 (H3/H4 cat\#16-0008 and H2A/H2B cat\#150311, EpiCypher Research Triangle Park, NC) nucleosomes were performed as previously described (Dimitriadis et al, 2010; Walkiewicz et al, 2014a). Chromatin from HeLa cells were obtained from fractions 6 and 7 of a glycerol density gradient (containing on average tri-, tetra-, and penta-nucleosome arrays). These samples were subjected to immuno-AFM as described previously (M. E. Browning-Kelley et al, 1997; Cheung \& Walker, 2008; Banerjee et al, 2012). An aliquot of each sample was imaged by AFM in non-contact tapping mode. The remainder of the samples were incubated overnight at $4^{\circ} \mathrm{C}$ with anti-CENP-A antibody (Abcam cat \#ab13939) in an end-over-end rotator before being imaged by AFM. Finally, these samples were incubated with anti-mouse secondary antibody (Li-Cor's IRDye 800CW Donkey anti-mouse IgG cat\#92532212) for an hour at room-temperature in an end-over-end rotator and imaged by AFM in noncontact tapping mode. We analyzed the height profiles of the nucleosomes and antibody complexes as described above.

\section{Transmission electron microscopy}

For transmission electron microscopy (TEM), the N-ChIP samples were fixed by adding $0.1 \%$ glutaraldehyde at $4^{\circ} \mathrm{C}$ for 5 hours, followed by 12 -hour dialysis against $\mathrm{HNE}$ buffer (10 mM HEPES pH=7.0, $5 \mathrm{mM} \mathrm{NaCl}$, 0.1 mM EDTA) in 20,000 MWCO membranes dialysis cassettes (Slide-A-Lyzer Dialysis Cassette, ThermoFisher cat \#66005) at $4^{\circ} \mathrm{C}$. The dialyzed samples were diluted to about $1 \mu \mathrm{g} / \mathrm{mL}$ concentration with $67.5 \mathrm{mM} \mathrm{NaCl}$, applied to carbon-coated and glowdischarged EM grids (T1000-Cu, Electron Microscopy Sciences), and stained with 0.04\% uranyl acetate. Dark-field EM imaging was conducted at $120 \mathrm{kV}$ using JEM-1000 electron microscope 
(JEOL USA, Peabody, MA) with SC1000 ORIUS 11 megapixel CCD camera (Gatan, Inc. Warrendale, PA).

\section{Immunostaining of mitotic chromosomes}

HeLa cells were synchronized to mitosis with double thymidine block. Primary antibodies $\gamma$ H2A.X, CENP-C, and CENP-A were used at dilution 1:1000. Alexa secondary $(488,568,647)$ were used at dilution of 1:1000. Images were obtained using DeltaVision RT system fitted with a CoolSnap charged-coupled device camera and mounted on an Olympus IX70. Deconvolved IF images were processed using ImageJ. Mitotic defects (lagging chromosomes and/or multipolar spindles) were counted for 83 and 76 cells (mock, GFP-CENP-C, respectively).

\section{Quench pulse-chase immunofluorescence}

To quantify de novo assembled CENP-A particles, we transfected HeLa cells with SNAP-tagged CENP-A (generous gift from Dan Foltz) in combination with either empty vector or GFP-CENPC using the Amaxa Nucleofector kit R (Lonza Bioscience, Walkersville, MD) per instructions.

The quench pulse-chase experiment was performed according to Bodor et $\mathrm{al}^{17}$. In short, following transfection, cells were synchronized with double thymidine block. At the first release TMR-block (S9106S, New England Biolabs, Ipswich, MA) was added per manufactures instruction and incubated for $30 \mathrm{~min}$ at $37^{\circ} \mathrm{C}$, followed by three washes with cell culture media. At the second release TMR-Star (S9105S, New England Biolabs, Ipswich, MA) was added per manufactures instructions and incubated for $15 \mathrm{~min}$ at $37^{\circ} \mathrm{C}$, followed by three washes with cell culture media. Fourteen hours after adding TMR-Star, cells were fixed with 1\% paraformaldehyde in PEM (80 mM K-PIPES pH 6.8, 5 mM EGTA pH 7.0, $2 \mathrm{mM} \mathrm{MgCl}_{2}$ ) for 10 
min at RT. Next, cells were washed the cells three times with ice cold PEM. To extract soluble proteins, cells were incubated with $0.5 \%$ Triton-X in CSK (10 mM K-PIPES pH 6.8, $100 \mathrm{mM}$ $\mathrm{NaCl}, 300 \mathrm{mM}$ sucrose, $3 \mathrm{mM} \mathrm{MgCl} 2,1 \mathrm{mM} \mathrm{EGTA}$ ) for $5 \mathrm{~min}$ at $4^{\circ} \mathrm{C}$. The cells were rinsed with PEM and fixed for a second time with 4\% PFA in PEM for 20 min at $4^{\circ} \mathrm{C}$. Next, the cells were washed three times with PEM. Cells were permeabilized with $0.5 \%$ Triton-X in PEM for 5 min at RT and subsequently washes three times with PEM. Next, the cells were incubated in blocking solution (1X PBS, 3\% BSA, 5\% normal goat serum) for $1 \mathrm{hr}$ at $4^{\circ} \mathrm{C}$. CENP-A antibody (ab13979 1:1000) was added for $1 \mathrm{hr}$ at $4^{\circ} \mathrm{C}$, followed by three washes with 1X PBS-T. Anti-mouse secondary (Alexa-488 1:1000) was added for $1 \mathrm{hr}$ at $4^{\circ} \mathrm{C}$, followed by three $1 \mathrm{X}$ PBS-T and two 1X PBS washes. Following air-drying, cells were mounted with Vectashield with DAPI (H1200, Vector Laboratories, Burlingame, CA) and the coverslips were sealed with nail polish. Images were collected using a DeltaVision RT system fitted with a CoolSnap charged-coupled device camera and mounted on an Olympus IX70. Deconvolved IF images were processed using ImageJ. From up to 22 nuclei, colocalizing CENP-A and TMR-Star foci signal were collected, as well directly neighboring regions. Background signal intensity was deducted from corresponding CENP-A and TMR-Star signal intensity before the ratio CENP-A/TMR-Star was determined. Graphs were prepared using the ggplot2 package for R.

\section{ChIP-seq}

CENP-C N-ChIP followed by ACA N-ChIP was conducted, as well as an IgG N-ChIP and input control as described above. Next, DNA was isolated by first proteinase K treated the samples, followed by DNA extraction by phenol chloroform. The samples were used to prepare libraries for PacBio single-molecule sequencing as described in manufacturer's protocol (PacBio, Menlo 
Park, CA). Libraries were produced and loaded on ZWM chip either by diffusion or following size selection of the inserts ( $>1000 \mathrm{bp}$ ) for all four samples. Subsequently, the reads were sequenced on the PacBio RS II operated by Advanced Technology Center, NCI (Frederick, MD). Sequence reads were mapped to either sequences in RepBase, the consensus sequence used by (Hasson et al, 2013), and the consensus sequences used by (Henikoff et al, 2015). The sequence data can be found under GEO accession number GSE129351.

\section{Quantification and statistical analyses}

Significant differences for Western blot quantification and nucleosome height measurements from AFM analyses were performed using either paired or two-sided t-test as described in the figure legends. Significance was determined at $\mathrm{p}<0.05$.

\section{Footnotes}

Authors contributions: D.P.M., T.R., and Y.D. designed research; D.P.M., T.R, B.M., S.A.G., and D.S. performed research; D.P.M., T.R., B.M., S.A.G., D.S., and Y.D. analyzed data; D.P.M. prepared figures; and D.P.M. and Y.D. wrote the paper; all authors editing the paper.

The authors declare no conflict of interest.

\section{Acknowledgements}

We thank Drs. Tom Misteli and Sam John, and members of the CSEM laboratory for critical comments and suggestions. We thank Dr. Kerry Bloom for encouraging us to purify kinetochore bound centromeric chromatin. We acknowledge Dr. Andrea Musacchio's suggestion to test for 
CENP-C depletion in a previous version of this manuscript.. This work utilized the computational resources of the NIH HPC Biowulf cluster (http://hpc.nih.gov). Y.D. and T.R, B.M., D.S., and D.P.M. were supported by the Intramural Research Program of the Center for Cancer Research at the National Cancer Institute/NIH. S.A.G. was supported by NSF grant 1516999.

\section{References}

Ali-Ahmad A, Bilokapić S, Schäfer IB, Halić M \& Sekulić N (2019) CENP -C unwraps the human CENP -A nucleosome through the H2A C-terminal tail. EMBO Rep. 20: e48913 Available at: http://www.ncbi.nlm.nih.gov/pubmed/31475439 [Accessed October 21, 2019]

Athwal RK, Walkiewicz MP, Baek S, Fu S, Bui M, Camps J, Ried T, Sung M-H \& Dalal Y (2015) CENP-A nucleosomes localize to transcription factor hotspots and subtelomeric sites in human cancer cells. Epigenetics Chromatin 8: 2 Available at: http://www.ncbi.nlm.nih.gov/pubmed/25788983 [Accessed October 21, 2019]

Bailey AO, Panchenko T, Shabanowitz J, Lehman SM, Bai DL, Hunt DF, Black BE \& Foltz DR (2016) Identification of the Post-translational Modifications Present in Centromeric Chromatin. Mol. Cell. Proteomics 15: 918-931 Available at: http://www.ncbi.nlm.nih.gov/pubmed/26685127 [Accessed October 21, 2019]

Banerjee S, M A, Rakshit T, Roy NS, Kundu TK, Roy S \& Mukhopadhyay R (2012) Structural features of human histone acetyltransferase p300 and its complex with p53. FEBS Lett. 586: 3793-3798 Available at: http://doi.wiley.com/10.1016/j.febslet.2012.09.012 [Accessed April 2, 2019]

Bergmann JH, Rodríguez MG, Martins NMC, Kimura H, Kelly DA, Masumoto H, Larionov V, 
Jansen LET \& Earnshaw WC (2011) Epigenetic engineering shows H3K4me2 is required for HJURP targeting and CENP-A assembly on a synthetic human kinetochore. EMBOJ.

30: 328-340 Available at: http://www.ncbi.nlm.nih.gov/pubmed/21157429 [Accessed October 21, 2019]

Bloom KS \& Carbon J (1982) Yeast centromere DNA is in a unique and highly ordered structure in chromosomes and small circular minichromosomes. Cell 29: 305-317 Available at: http://www.ncbi.nlm.nih.gov/pubmed/6288253 [Accessed October 21, 2019]

Blower MD, Sullivan BA \& Karpen GH (2002) Conserved organization of centromeric chromatin in flies and humans. Dev. Cell 2: 319-330

Bobkov GOM, Gilbert N \& Heun P (2018) Centromere transcription allows CENP-A to transit from chromatin association to stable incorporation. J. Cell Biol. 217: 1957-1972 Available at: http://www.ncbi.nlm.nih.gov/pubmed/29626011 [Accessed October 21, 2019]

Bodor DL, Mata JF, Sergeev M, David AF, Salimian KJ, Panchenko T, Cleveland DW, Black BE, Shah J V \& Jansen LE (2014) The quantitative architecture of centromeric chromatin. Elife

Bodor DL, Rodríguez MG, Moreno N \& Jansen LET (2012) Analysis of Protein Turnover by Quantitative SNAP-Based Pulse-Chase Imaging. In Current Protocols in Cell Biology p Unit8.8. Hoboken, NJ, USA: John Wiley \& Sons, Inc. Available at: http://www.ncbi.nlm.nih.gov/pubmed/23129118 [Accessed October 21, 2019]

Bodor DL, Valente LP, Mata JF, Black BE \& Jansen LET (2013) Assembly in G1 phase and long-term stability are unique intrinsic features of CENP-A nucleosomes. Mol. Biol. Cell Bui M, Dimitriadis EK, Hoischen C, An E, Quénet D, Giebe S, Nita-Lazar A, Diekmann S \& Dalal Y (2012) Cell-Cycle-Dependent Structural Transitions in the Human CENP-A 
Nucleosome In Vivo. Cell 150: 317-326 Available at:

http://www.ncbi.nlm.nih.gov/pubmed/22817894 [Accessed October 21, 2019]

Bui M, Pitman M, Nuccio A, Roque S, Donlin-Asp PG, Nita-Lazar A, Papoian GA \& Dalal Y

(2017) Internal modifications in the CENP-A nucleosome modulate centromeric dynamics.

Epigenetics Chromatin 10: 17 Available at:

http://epigeneticsandchromatin.biomedcentral.com/articles/10.1186/s13072-017-0124-6

[Accessed October 21, 2019]

Bui M, Walkiewicz MP, Dimitriadis EK \& Dalal Y (2013) The CENP-A nucleosome: a battle between Dr Jekyll and Mr Hyde. Nucleus 4: 37-42 Available at:

http://www.tandfonline.com/doi/abs/10.4161/nucl.23588 [Accessed October 21, 2019]

Carroll CW, Milks KJ \& Straight AF (2010) Dual recognition of CENP-A nucleosomes is required for centromere assembly. J. Cell Biol. 189: 1143-55 Available at:

http://www.jcb.org/lookup/doi/10.1083/jcb.201001013 [Accessed October 21, 2019]

Catania S, Pidoux AL \& Allshire RC (2015) Sequence features and transcriptional stalling within centromere DNA promote establishment of CENP-A chromatin. PLoS Genet. 11: e1004986 Available at: http://dx.plos.org/10.1371/journal.pgen.1004986 [Accessed October 21, 2019]

Chan FL \& Wong LH (2012) Transcription in the maintenance of centromere chromatin identity. Nucleic Acids Res. 40: 11178-11188 Available at: http://www.ncbi.nlm.nih.gov/pubmed/23066104 [Accessed October 21, 2019]

Cheeseman IM (2014) The Kinetochore. Cold Spring Harb. Perspect. Biol. 6: a015826-a015826 Available at: http://www.ncbi.nlm.nih.gov/pubmed/24984773 [Accessed April 2, 2019]

Cheeseman IM, Chappie JS, Wilson-Kubalek EM \& Desai A (2006) The conserved KMN network constitutes the core microtubule-binding site of the kinetochore. Cell 127: 983-97 
Available at: https://linkinghub.elsevier.com/retrieve/pii/S0092867406013456 [Accessed October 21, 2019]

Cheung JWC \& Walker GC (2008) Immuno-Atomic Force Microscopy Characterization of Adsorbed Fibronectin. Langmuir 24: 13842-13849 Available at:

http://www.ncbi.nlm.nih.gov/pubmed/19360949 [Accessed April 2, 2019]

Choi ES, Strålfors A, Castillo AG, Durand-Dubief M, Ekwall K \& Allshire RC (2011)

Identification of noncoding transcripts from within CENP-A chromatin at fission yeast centromeres. J. Biol. Chem. 286: 23600-7 Available at:

http://www.jbc.org/lookup/doi/10.1074/jbc.M111.228510 [Accessed October 21, 2019]

Chueh AC, Northrop EL, Brettingham-Moore KH, Choo KHA \& Wong LH (2009) LINE

retrotransposon RNA is an essential structural and functional epigenetic component of a core neocentromeric chromatin. PLoS Genet. 5: e1000354 Available at:

http://dx.plos.org/10.1371/journal.pgen.1000354 [Accessed October 21, 2019]

Comings DE \& Okada TA (1970) Whole-mount electron microscopy of the centromere region of metacentric and telocentric mammalian chromosomes. Cytogenetics 9: 436-49 Available at: http://www.ncbi.nlm.nih.gov/pubmed/5518566 [Accessed April 1, 2019]

Cooper JL \& Henikoff S (2004) Adaptive evolution of the histone fold domain in centromeric histones. Mol. Biol. Evol 21: 1712-1718

Dalal Y, Wang H, Lindsay S \& Henikoff S (2007) Tetrameric structure of centromeric nucleosomes in interphase Drosophila cells. PLoS Biol. 5: e218 Available at: http://dx.plos.org/10.1371/journal.pbio.0050218 [Accessed October 21, 2019]

DeLuca JG \& Musacchio A (2012) Structural organization of the kinetochore-microtubule interface. Curr. Opin. Cell Biol. 24: 48-56 Available at: 
http://www.ncbi.nlm.nih.gov/pubmed/22154944 [Accessed October 21, 2019]

Díaz-Ingelmo O, Martínez-García B, Segura J, Valdés A \& Roca J (2015) DNA Topology and

Global Architecture of Point Centromeres. Cell Rep. 13: 667-677 Available at:

https://linkinghub.elsevier.com/retrieve/pii/S2211124715010505 [Accessed October 21, 2019]

Dimitriadis EK, Weber C, Gill RK, Diekmann S \& Dalal Y (2010) Tetrameric organization of vertebrate centromeric nucleosomes. Proc. Natl. Acad. Sci. U. S. A. 107: 20317-22

Available at: http://www.pnas.org/cgi/doi/10.1073/pnas.1009563107 [Accessed October 21, 2019]

Earnshaw WC \& Rothfield N (1985) Identification of a family of human centromere proteins using autoimmune sera from patients with scleroderma. Chromosoma 91: 313-321

Available at: http://link.springer.com/10.1007/BF00328227 [Accessed October 21, 2019]

Esponda P (1978) Cytochemistry of kinetochores under electron microscopy. Exp. Cell Res. 114:

247-52 Available at: http://www.ncbi.nlm.nih.gov/pubmed/79490 [Accessed April 1, 2019]

Falk SJ, Guo LY, Sekulic N, Smoak EM, Mani T, Logsdon GA, Gupta K, Jansen LET, Van Duyne GD, Vinogradov SA, Lampson MA \& Black BE (2015) Chromosomes. CENP-C reshapes and stabilizes CENP-A nucleosomes at the centromere. Science 348: 699-703 Available at: http://www.sciencemag.org/cgi/doi/10.1126/science.1259308 [Accessed October 21, 2019]

Falk SJ, Lee J, Sekulic N, Sennett MA, Lee T-H \& Black BE (2016) CENP-C directs a structural transition of CENP-A nucleosomes mainly through sliding of DNA gyres. Nat. Struct. Mol. Biol. 23: 204-208 Available at: http://www.nature.com/articles/nsmb.3175 [Accessed October 21, 2019] 
Ferri F, Bouzinba-Segard H, Velasco G, Hubé F \& Francastel C (2009) Non-coding murine centromeric transcripts associate with and potentiate Aurora B kinase. Nucleic Acids Res. 37: 5071-80 Available at: https://academic.oup.com/nar/articlelookup/doi/10.1093/nar/gkp529 [Accessed October 21, 2019]

Fierz B \& Poirier MG (2019) Biophysics of Chromatin Dynamics. Annu. Rev. Biophys.

Foltz DR, Jansen LET, Black BE, Bailey AO, Yates JR \& Clevel DW (2006) The human CENPA centromeric nucleosome-associated complex. Nat. Cell Biol 8: 458-469

Fukagawa T, Pendon C, Morris J \& Brown W (1999) CENP-C is necessary but not sufficient to induce formation of a functional centromere. EMBO J. 18: 4196-209 Available at: http://www.ncbi.nlm.nih.gov/pubmed/10428958 [Accessed October 21, 2019]

Furuyama T, Codomo CA \& Henikoff S (2013) Reconstitution of hemisomes on budding yeast centromeric DNA. Nucleic Acids Res. 41: 5769-83 Available at: https://academic.oup.com/nar/article/41/11/5769/2411649 [Accessed October 21, 2019] Furuyama T \& Henikoff S (2009) Centromeric nucleosomes induce positive supercoils. Cell 138: $104-113$

Gonen S, Akiyoshi B, Iadanza MG, Shi D, Duggan N, Biggins S \& Gonen T (2012) The structure of purified kinetochores reveals multiple microtubule-attachment sites. Nat. Struct. Mol. Biol. 19: 925-9 Available at: http://www.nature.com/articles/nsmb.2358 [Accessed October 21, 2019]

Gregan J, Polakova S, Zhang L, Tolić-Nørrelykke IM \& Cimini D (2011) Merotelic kinetochore attachment: causes and effects. Trends Cell Biol. 21: 374-381 Available at: http://www.ncbi.nlm.nih.gov/pubmed/21306900 [Accessed October 21, 2019] Grenfell AW, Heald R \& Strzelecka M (2016) Mitotic noncoding RNA processing promotes 
kinetochore and spindle assembly in Xenopus. J. Cell Biol. 214: 133-141 Available at:

http://www.ncbi.nlm.nih.gov/pubmed/27402954 [Accessed October 21, 2019]

Guo LY, Allu PK, Zandarashvili L, McKinley KL, Sekulic N, Dawicki-McKenna JM, Fachinetti D, Logsdon GA, Jamiolkowski RM, Cleveland DW, Cheeseman IM \& Black BE (2017)

Centromeres are maintained by fastening CENP-A to DNA and directing an arginine anchor-dependent nucleosome transition. Nat. Commun. 8: 15775 Available at: http://www.nature.com/articles/ncomms15775 [Accessed October 21, 2019]

Hasson D, Panchenko T, Salimian KJ, Salman MU, Sekulic N, Alonso A, Warburton PE \& Black BE (2013) The octamer is the major form of CENP-A nucleosomes at human centromeres. Nat. Struct. Mol. Biol. 20: 687-95 Available at:

http://www.nature.com/articles/nsmb.2562 [Accessed October 21, 2019]

Henikoff JG, Thakur J, Kasinathan S \& Henikoff S (2015) A unique chromatin complex occupies young $\alpha$-satellite arrays of human centromeres. Sci. Adv. 1: e1400234 Available at: http://advances.sciencemag.org/lookup/doi/10.1126/sciadv.1400234 [Accessed October 21, 2019]

Henikoff S, Ahmad K \& Malik HS (2001) The centromere paradox: stable inheritance with rapidly evolving DNA. Science 293: 1098-102 Available at:

http://www.sciencemag.org/cgi/doi/10.1126/science.1062939 [Accessed October 21, 2019] Henikoff S \& Dalal Y (2005) Centromeric chromatin: what makes it unique? Curr. Opin. Genet. Dev. 15: 177-184 Available at: http://www.ncbi.nlm.nih.gov/pubmed/15797200 [Accessed October 21, 2019]

Henikoff S, Ramachandran S, Krassovsky K, Bryson TD, Codomo CA, Brogaard K, Widom J, Wang J-P \& Henikoff JG (2014) The budding yeast Centromere DNA Element II wraps a 
stable Cse4 hemisome in either orientation in vivo. Elife 3: e01861 Available at:

https://elifesciences.org/articles/01861 [Accessed October 21, 2019]

Howman E V, Fowler KJ, Newson AJ, Redward S, MacDonald AC, Kalitsis P \& Choo KH (2000) Early disruption of centromeric chromatin organization in centromere protein A (Cenpa) null mice. Proc. Natl. Acad. Sci. U. S. A. 97: 1148-53 Available at:

http://www.pnas.org/cgi/doi/10.1073/pnas.97.3.1148 [Accessed October 21, 2019]

Kalitsis P, Fowler KJ, Earle E, Hill J \& Choo KH (1998) Targeted disruption of mouse centromere protein $\mathrm{C}$ gene leads to mitotic disarray and early embryo death. Proc. Natl. Acad. Sci. U. S. A. 95: 1136-41 Available at:

http://www.pnas.org/cgi/doi/10.1073/pnas.95.3.1136 [Accessed October 21, 2019]

Kato H, Jiang J, Zhou B-R, Rozendaal M, Feng H, Ghirlando R, Xiao TS, Straight AF \& Bai Y (2013) A conserved mechanism for centromeric nucleosome recognition by centromere protein CENP-C. Science 340: 1110-3 Available at: http://www.sciencemag.org/cgi/doi/10.1126/science.1235532 [Accessed October 21, 2019] Kim SH, Vlijm R, van der Torre J, Dalal Y \& Dekker C (2016) CENP-A and H3 Nucleosomes Display a Similar Stability to Force-Mediated Disassembly. PLoS One 11: e0165078 Available at: http://dx.plos.org/10.1371/journal.pone.0165078 [Accessed October 21, 2019] Kingston IJ, Yung JSY \& Singleton MR (2011) Biophysical characterization of the centromerespecific nucleosome from budding yeast. J. Biol. Chem. 286: 4021-6 Available at: http://www.jbc.org/lookup/doi/10.1074/jbc.M110.189340 [Accessed October 21, 2019]

Klare K, Weir JR, Basilico F, Zimniak T, Massimiliano L, Ludwigs N, Herzog F \& Musacchio A (2015) CENP-C is a blueprint for constitutive centromere-associated network assembly within human kinetochores. J. Cell Biol. 210: 11-22 Available at: 
http://www.jcb.org/lookup/doi/10.1083/jcb.201412028 [Accessed October 21, 2019]

Klemm SL, Shipony Z \& Greenleaf WJ (2019) Chromatin accessibility and the regulatory epigenome. Nat. Rev. Genet. 20: 207-220 Available at:

http://www.ncbi.nlm.nih.gov/pubmed/30675018 [Accessed October 22, 2019]

Krassovsky K, Henikoff JG \& Henikoff S (2012) Tripartite organization of centromeric

chromatin in budding yeast. Proc. Natl. Acad. Sci. 109: 243-248 Available at:

http://www.pnas.org/cgi/doi/10.1073/pnas.1118898109 [Accessed October 21, 2019]

Kwon M-S, Hori T, Okada M \& Fukagawa T (2007) CENP-C Is Involved in Chromosome

Segregation, Mitotic Checkpoint Function, and Kinetochore Assembly. Mol. Biol. Cell 18:

2155-2168 Available at: http://www.ncbi.nlm.nih.gov/pubmed/17392512 [Accessed

October 21, 2019]

Kyriacou E \& Heun P (2018) High-resolution mapping of centromeric protein association using

APEX-chromatin fibers. Epigenetics Chromatin 11: 68 Available at:

http://www.ncbi.nlm.nih.gov/pubmed/30445992 [Accessed April 2, 2019]

Lacoste N, Woolfe A, Tachiwana H, Garea AV, Barth T, Cantaloube S, Kurumizaka H, Imhof A \& Almouzni G (2014) Mislocalization of the centromeric histone variant CenH3/CENP-A in human cells depends on the chaperone DAXX. Mol. Cell 53: 631-44 Available at: https://linkinghub.elsevier.com/retrieve/pii/S1097276514000793 [Accessed October 21, 2019]

Li F, Sonbuchner L, Kyes SA, Epp C \& Deitsch KW (2008) Nuclear non-coding RNAs are transcribed from the centromeres of Plasmodium falciparum and are associated with centromeric chromatin. J. Biol. Chem. 283: 5692-8 Available at: http://www.jbc.org/lookup/doi/10.1074/jbc.M707344200 [Accessed October 21, 2019] 
Ling YH \& Yuen KWY (2019) Point centromere activity requires an optimal level of centromeric noncoding RNA. Proc. Natl. Acad. Sci. U. S. A. 116: 6270-6279 Available at: http://www.pnas.org/lookup/doi/10.1073/pnas.1821384116 [Accessed October 21, 2019]

M. E. Browning-Kelley, K. Wadu-Mesthrige, V. Hari and \& G. Y. Liu (1997) Atomic Force Microscopic Study of Specific Antigen/Antibody Binding. Langmuir 13: 323-50 Available at: https://pubs.acs.org/doi/10.1021/la960918x [Accessed October 21, 2019]

Maeshima K, Ide S \& Babokhov M (2019) Dynamic chromatin organization without the 30-nm fiber. Curr. Opin. Cell Biol. 58: 95-104 Available at: http://www.ncbi.nlm.nih.gov/pubmed/30908980 [Accessed October 22, 2019]

Maheshwari S, Tan EH, West A, Franklin FCH, Comai L \& Chan SWL (2015) Naturally occurring differences in $\mathrm{CENH} 3$ affect chromosome segregation in zygotic mitosis of hybrids. PLoS Genet. 11: e1004970 Available at:

https://dx.plos.org/10.1371/journal.pgen.1004970 [Accessed October 21, 2019]

Malik HS \& Henikoff S (2001) Adaptive evolution of Cid, a centromere-specific histone in Drosophila. Genetics 157: 1293-8 Available at:

http://www.ncbi.nlm.nih.gov/pubmed/11238413 [Accessed October 21, 2019]

Malik HS \& Henikoff S (2003) Phylogenomics of the nucleosome. Nat. Struct. Biol 10: 882-891

Malik N, Dantu SC, Shukla S, Kombrabail M, Ghosh SK, Krishnamoorthy G \& Kumar A (2018) Conformational flexibility of histone variant CENP-ACse4 is regulated by histone H4: A mechanism to stabilize soluble Cse4. J. Biol. Chem. 293: 20273-20284 Available at: http://www.jbc.org/lookup/doi/10.1074/jbc.RA118.004141 [Accessed October 21, 2019] McEwen BF, Hsieh CE, Mattheyses AL \& Rieder CL (1998) A new look at kinetochore structure in vertebrate somatic cells using high-pressure freezing and freeze substitution. 
Chromosoma 107: 366-75 Available at: http://www.ncbi.nlm.nih.gov/pubmed/9914368

[Accessed April 1, 2019]

McKinley KL \& Cheeseman IM (2016) The molecular basis for centromere identity and

function. Nat. Rev. Mol. Cell Biol. 17: 16-29 Available at:

http://www.ncbi.nlm.nih.gov/pubmed/26601620 [Accessed October 21, 2019]

McNulty SM, Sullivan LL \& Sullivan BA (2017) Human Centromeres Produce ChromosomeSpecific and Array-Specific Alpha Satellite Transcripts that Are Complexed with CENP-A and CENP-C. Dev. Cell 42: 226-240.e6 Available at:

https://linkinghub.elsevier.com/retrieve/pii/S1534580717305439 [Accessed October 21, 2019]

Melters DP, Bradnam KR, Young HA, Telis N, May MR, Ruby JG, Sebra R, Peluso P, Eid J, Rank D, Garcia JF, DeRisi JL, Smith T, Tobias C, Ross-Ibarra J, Korf I \& Chan SWL (2013) Comparative analysis of tandem repeats from hundreds of species reveals unique insights into centromere evolution. Genome Biol. 14: R10 Available at: http://genomebiology.biomedcentral.com/articles/10.1186/gb-2013-14-1-r10 [Accessed October 21, 2019]

Melters DP, Nye J, Zhao H \& Dalal Y (2015) Chromatin dynamics in vivo: A game of musical chairs. Genes (Basel). 6:

Melters DP, Pitman M, Rakshit T, Dimitriadis EK, Bui M, Papoian GA \& Dalal Y (2019) Intrinsic elasticity of nucleosomes is encoded by histone variants and calibrated by their binding partners. Proc Natl Acad Sci US A: In Press Available at: https://www.biorxiv.org/content/10.1101/392787v4 [Accessed July 19, 2019] Mendiburo MJ, Padeken J, Fulop S, Schepers A \& Heun P (2011) Drosophila CENH3 Is 
Sufficient for Centromere Formation. Science (80-. ). 334: 686-690 Available at:

http://www.ncbi.nlm.nih.gov/pubmed/22053052 [Accessed October 21, 2019]

Meraldi P, McAinsh AD, Rheinbay E \& Sorger PK (2006) Phylogenetic and structural analysis of centromeric DNA and kinetochore proteins. Genome Biol. 7: R23 Available at: http://genomebiology.biomedcentral.com/articles/10.1186/gb-2006-7-3-r23 [Accessed October 21, 2019]

Milks KJ, Moree B \& Straight AF (2009) Dissection of CENP-C-directed Centromere and Kinetochore Assembly. Mol. Biol. Cell

Müller S \& Almouzni G (2017) Chromatin dynamics during the cell cycle at centromeres. Nat. Rev. Genet. 18: 192-208 Available at: http://www.ncbi.nlm.nih.gov/pubmed/28138144 [Accessed October 21, 2019]

Nye J, Sturgill D, Athwal R \& Dalal Y (2018) HJURP antagonizes CENP-A mislocalization driven by the H3.3 chaperones HIRA and DAXX. PLoS One 13: e0205948 Available at: http://www.ncbi.nlm.nih.gov/pubmed/30365520 [Accessed October 21, 2019]

Ohkuni K \& Kitagawa K (2011) Endogenous transcription at the centromere facilitates centromere activity in budding yeast. Curr. Biol. 21: 1695-703 Available at: https://linkinghub.elsevier.com/retrieve/pii/S0960982211009626 [Accessed October 21, 2019]

Padeganeh A, Ryan J, Boisvert J, Ladouceur A-M, Dorn JF \& Maddox PS (2013) Octameric CENP-A nucleosomes are present at human centromeres throughout the cell cycle. Curr. Biol. 23: 764-9 Available at: https://linkinghub.elsevier.com/retrieve/pii/S0960982213003394 [Accessed October 21, 2019] 
Palmer DK, O’Day K, Trong HL, Charbonneau H \& Margolis RL (1991) Purification of the centromere-specific protein CENP-A and demonstration that it is a distinctive histone. Proc. Natl. Acad. Sci. U. S. A. 88: 3734-8 Available at:

http://www.pnas.org/cgi/doi/10.1073/pnas.88.9.3734 [Accessed October 21, 2019]

Pesenti ME, Weir JR \& Musacchio A (2016) Progress in the structural and functional characterization of kinetochores. Curr. Opin. Struct. Biol. 37: 152-63 Available at: https://linkinghub.elsevier.com/retrieve/pii/S0959440X16300124 [Accessed October 21, 2019]

Pettersen EO, Bakke O, Lindmo T \& Oftebro R (1977) Cell Cycle Characteristics of Synchornized and Asychronous Populations of Human Cells and Effect of Cooling of Selected Mitotic Cells. Cell Prolif.

Polach KJ \& Widom J (1995) Mechanism of protein access to specific DNA sequences in chromatin: a dynamic equilibrium model for gene regulation. J. Mol. Biol. 254: 130-49 Available at: https://linkinghub.elsevier.com/retrieve/pii/S0022283685706067 [Accessed October 21, 2019]

Przewloka MR, Zhang W, Costa P, Archambault V, D’Avino PP, Lilley KS, Laue ED, McAinsh AD \& Glover DM (2007) Molecular analysis of core kinetochore composition and assembly in Drosophila melanogaster. PLoS One 2: e478 Available at: http://dx.plos.org/10.1371/journal.pone.0000478 [Accessed October 21, 2019]

Quénet D \& Dalal Y (2014) A long non-coding RNA is required for targeting centromeric protein A to the human centromere. Elife

Rattner JB, Branch A \& Hamkalo BA (1975) Electron microscopy of whole mount metaphase chromosomes. Chromosoma 52: 329-38 Available at: 
http://www.ncbi.nlm.nih.gov/pubmed/1192902 [Accessed April 1, 2019]

Régnier V, Vagnarelli P, Fukagawa T, Zerjal T, Burns E, Trouche D, Earnshaw W \& Brown W (2005) CENP-A is required for accurate chromosome segregation and sustained kinetochore association of BubR1. Mol. Cell. Biol. 25: 3967-81 Available at:

http://mcb.asm.org/cgi/doi/10.1128/MCB.25.10.3967-3981.2005 [Accessed October 21, 2019]

Remnant L, Booth DG, Vargiu G, Spanos C, Kerr ARW \& Earnshaw WC (2019) In vitro BioID: mapping the CENP-A microenvironment with high temporal and spatial resolution. Mol.

Biol. Cell 30: 1314-1325 Available at: http://www.ncbi.nlm.nih.gov/pubmed/30892990

[Accessed October 21, 2019]

Ribeiro SA, Vagnarelli P, Dong Y, Hori T, McEwen BF, Fukagawa T, Flors C \& Earnshaw WC (2010) A super-resolution map of the vertebrate kinetochore. Proc. Natl. Acad. Sci. U. S. A. 107: 10484-9 Available at: http://www.pnas.org/cgi/doi/10.1073/pnas.1002325107 [Accessed October 21, 2019]

Rošić S, Köhler F \& Erhardt S (2014) Repetitive centromeric satellite RNA is essential for kinetochore formation and cell division. J. Cell Biol. 207: 335-49 Available at: http://www.jcb.org/lookup/doi/10.1083/jcb.201404097 [Accessed October 21, 2019] Roulland Y, Ouararhni K, Naidenov M, Ramos L, Shuaib M, Syed SH, Lone IN, Boopathi R, Fontaine E, Papai G, Tachiwana H, Gautier T, Skoufias D, Padmanabhan K, Bednar J, Kurumizaka H, Schultz P, Angelov D, Hamiche A \& Dimitrov S (2016) The Flexible Ends of CENP-A Nucleosome Are Required for Mitotic Fidelity. Mol. Cell 63: 674-685

Available at: http://www.ncbi.nlm.nih.gov/pubmed/27499292 [Accessed October 21, 2019] Rudd MK, Wray GA \& Willard HF (2005) The evolutionary dynamics of $\alpha$-satellite. Genome 
Res. 16: 88-96 Available at: http://www.ncbi.nlm.nih.gov/pubmed/16344556 [Accessed October 21, 2019]

Salmon E., Cimini D, Cameron L. \& DeLuca J. (2005) Merotelic kinetochores in mammalian tissue cells. Philos. Trans. R. Soc. B Biol. Sci. 360: 553-568 Available at: http://www.ncbi.nlm.nih.gov/pubmed/15897180 [Accessed October 21, 2019]

Sanulli S, Trnka MJ, Dharmarajan V, Tibble RW, Pascal BD, Burlingame AL, Griffin PR, Gross JD \& Narlikar GJ (2019) HP1 reshapes nucleosome core to promote heterochromatin phase separation. Nature Available at: http://www.ncbi.nlm.nih.gov/pubmed/31618757 [Accessed October 22, 2019]

Saunders M, Fitzgerald-Hayes M \& Bloom K (1988) Chromatin structure of altered yeast centromeres. Proc. Natl. Acad. Sci. 85: 175-179 Available at: http://www.ncbi.nlm.nih.gov/pubmed/2829168 [Accessed October 21, 2019]

Silkworth WT, Nardi IK, Scholl LM \& Cimini D (2009) Multipolar spindle pole coalescence is a major source of kinetochore mis-attachment and chromosome mis-segregation in cancer cells. PLoS One 4: e6564 Available at: http://dx.plos.org/10.1371/journal.pone.0006564 [Accessed October 21, 2019]

Skene PJ \& Henikoff S (2015) A simple method for generating high-resolution maps of genomewide protein binding. Elife 4: e09225 Available at: https://elifesciences.org/articles/09225 [Accessed October 21, 2019]

Smoak EM, Stein P, Schultz RM, Lampson MA \& Black BE (2016) Long-Term Retention of CENP-A Nucleosomes in Mammalian Oocytes Underpins Transgenerational Inheritance of Centromere Identity. Curr. Biol. 26: 1110-6 Available at: https://linkinghub.elsevier.com/retrieve/pii/S0960982216301725 [Accessed October 21, 
2019]

Stumme-Diers MP, Banerjee S, Hashemi M, Sun Z \& Lyubchenko YL (2018) Nanoscale dynamics of centromere nucleosomes and the critical roles of CENP-A. Nucleic Acids Res.

Sullivan BA \& Karpen GH (2004) Centromeric chromatin exhibits a histone modification pattern that is distinct from both euchromatin and heterochromatin. Nat. Struct. Mol. Biol. 11: 1076-83 Available at: http://www.nature.com/articles/nsmb845 [Accessed October 21, 2019]

Suzuki A, Badger BL \& Salmon ED (2015) A quantitative description of Ndc80 complex linkage to human kinetochores. Nat. Commun. 6: 8161 Available at: http://www.nature.com/articles/ncomms9161 [Accessed October 21, 2019]

Suzuki A, Hori T, Nishino T, Usukura J, Miyagi A, Morikawa K \& Fukagawa T (2011) Spindle microtubules generate tension-dependent changes in the distribution of inner kinetochore proteins. J. Cell Biol. 193: 125-40 Available at: http://www.jcb.org/lookup/doi/10.1083/jcb.201012050 [Accessed October 21, 2019]

Tachiwana H, Kagawa W, Shiga T, Osakabe A, Miya Y, Saito K, Hayashi-Takanaka Y, Oda T, Sato M, Park S-Y, Kimura H \& Kurumizaka H (2011) Crystal structure of the human centromeric nucleosome containing CENP-A. Nature 476: 232-235 Available at: http://www.ncbi.nlm.nih.gov/pubmed/21743476 [Accessed October 21, 2019]

Talbert PB, Bryson TD \& Henikoff S (2004) Adaptive evolution of centromere proteins in plants and animals. J. Biol. 3: 18 Available at: http://www.ncbi.nlm.nih.gov/pubmed/15345035 [Accessed October 21, 2019]

Vargiu G, Makarov AA, Allan J, Fukagawa T, Booth DG \& Earnshaw WC (2017) Stepwise unfolding supports a subunit model for vertebrate kinetochores. Proc. Natl. Acad. Sci. U. S. 


\section{A. 114: 3133-3138 Available at:}

http://www.pnas.org/lookup/doi/10.1073/pnas.1614145114 [Accessed October 21, 2019]

Vlijm R, Kim SH, De Zwart PL, Dalal Y \& Dekker C (2017) The supercoiling state of DNA determines the handedness of both H3 and CENP-A nucleosomes. Nanoscale 9: 1862-1870 Available at: http://xlink.rsc.org/?DOI=C6NR06245H [Accessed October 21, 2019]

Walkiewicz MP, Bui M, Quénet D \& Dalal Y (2014a) Tracking histone variant nucleosomes across the human cell cycle using biophysical, biochemical, and cytological analyses.

Methods Mol. Biol. 1170: 589-615 Available at: http://link.springer.com/10.1007/978-14939-0888-2_34 [Accessed October 21, 2019]

Walkiewicz MP, Dimitriadis EK \& Dalal Y (2014b) CENP-A octamers do not confer a reduction in nucleosome height by AFM. Nat. Struct. Mol. Biol. 21: 2-3 Available at: http://www.ncbi.nlm.nih.gov/pubmed/24389541 [Accessed October 21, 2019]

Wang H, Dalal Y, Henikoff S \& Lindsay S (2008) Single-epitope recognition imaging of native chromatin. Access 9: 1-9

Waye JS \& Willard HF (1989) Human beta satellite DNA: genomic organization and sequence definition of a class of highly repetitive tandem DNA. Proc. Natl. Acad. Sci. U. S. A. 86: 6250-4 Available at: http://www.pnas.org/cgi/doi/10.1073/pnas.86.16.6250 [Accessed October 21, 2019]

Weir JR, Faesen AC, Klare K, Petrovic A, Basilico F, Fischböck J, Pentakota S, Keller J, Pesenti ME, Pan D, Vogt D, Wohlgemuth S, Herzog F \& Musacchio A (2016) Insights from biochemical reconstitution into the architecture of human kinetochores. Nature 537: 249253 Available at: http://www.nature.com/articles/nature19333 [Accessed October 21, 2019] Widom J (1998) Structure, Dynamics, and Function of Chromatin in vitro. Annu. Rev. Biophys. 
Biomol. Struct. 27: 285-327 Available at: http://www.ncbi.nlm.nih.gov/pubmed/9646870

[Accessed October 21, 2019]

Winogradoff D, Zhao H, Dalal Y \& Papoian GA (2015) Shearing of the CENP-A dimerization interface mediates plasticity in the octameric centromeric nucleosome. Sci. Rep. 5: 17038

Available at: http://www.nature.com/articles/srep17038 [Accessed October 21, 2019]

Wong LH, Brettingham-Moore KH, Chan L, Quach JM, Anderson MA, Northrop EL, Hannan R, Saffery R, Shaw ML, Williams E \& Choo KHA (2007) Centromere RNA is a key component for the assembly of nucleoproteins at the nucleolus and centromere. Genome Res. 17: 1146-60 Available at: http://www.genome.org/cgi/doi/10.1101/gr.6022807

[Accessed October 21, 2019]

Zhao H, Winogradoff D, Bui M, Dalal Y \& Papoian GA (2016) Promiscuous Histone MisAssembly Is Actively Prevented by Chaperones. J. Am. Chem. Soc. 138: 13207-13218 Available at: https://pubs.acs.org/doi/10.1021/jacs.6b05355 [Accessed October 21, 2019]

Zhao H, Winogradoff D, Dalal Y \& Papoian GA (2019) The Oligomerization Landscape of Histones. Biophys. J. 116: 1845-1855 Available at:

https://linkinghub.elsevier.com/retrieve/pii/S0006349519302784 [Accessed October 21, 2019]

Zhu J, Cheng KCL \& Yuen KWY (2018) Histone H3K9 and H4 Acetylations and Transcription Facilitate the Initial CENP-AHCP-3 Deposition and De Novo Centromere Establishment in Caenorhabditis elegans Artificial Chromosomes. Epigenetics Chromatin 11: 16 Available at: https://epigeneticsandchromatin.biomedcentral.com/articles/10.1186/s13072-018-0185-1 [Accessed October 21, 2019] 


\section{Figures legends}

\section{Figure 1. CENP-C binds a subset of CENP-A nucleosomes}

(A) Schematic of experimental set-up of serial chromatin immunoprecipitation. (B) Western blot analysis of the serial N-ChIP was performed and probed for H2A, H3, CENP-A, and CENP-C. (C) Quantification of CENP-A enrichment in either CENP-C or subsequent ACA N-ChIP or X-ChIP confirms the presence of two CENP-A populations (paired t-test; significance was determined at $p<0.05$ ). (D) A serial dilution of extracted nuclei was loaded side-by-side to a CENP-C N-ChIP followed by a CENP-A N-ChIP.

Figure 2. A small fraction of CENP-A stably associates with the inner kinetochore

(A) To determine if CENP-C N-ChIP also brought down kinetochore components, both CENP-A populations were purified and probed for the histones (H2A, H4, CENP-A), CENP-B, inner kinetochore components (CENP-W, CENP-T, CENP-I, CENP-N), and outer kinetochore components (MIS12, HEC1). (C) To determine whether histone H2A variants associate with CENP-A nucleosomes in complex with CENP-C or bulk CENP-A, we performed western blot analysis probing for $\gamma \mathrm{H} 2 \mathrm{~A} . \mathrm{X}, \mathrm{H} 2 \mathrm{~A} . \mathrm{Z}$, and macroH2A. (D) Quantification of four independent experiments revealed that none of the H2A variants was enriched in either CENP-A population. As a control, we measured the relative amount of $\mathrm{H} 2 \mathrm{~B}$ over $\mathrm{H} 4$ (paired t-test; significance was determined at $p<0.05$ ).

\section{Figure 3. Immuno-AFM confirms CENP-C associates with CENP-A nucleosomes}

(A) To confirm that CENP-C associated with CENP-A nucleosomes, we performed immuno-AFM on in vitro reconstituting $\mathrm{H} 3$ and CENP-A nucleosomes in parallel to extracted bulk and CENP-C associated chromatin. (B) Representative images for three conditions (no antibody, $1^{\circ}$ antibody, $1^{\circ}$ plus $2^{\circ}$ antibodies) per sample. The scale bar is $30 \mathrm{~nm}$. (C) Height measurement of all three conditions were plotted per sample, showing that anti-CENP-A antibody only recognized in vitro reconstituted CENP-A nucleosomes and nucleosomes associated with CENP-C, confirming that CENP-C indeed strongly associated with CENP-A nucleosomes.

\section{Figure 4. Purified CENP-C complex are associated with stable octameric CENP-A nucleosomes}

Chromatin was extracted from HeLa cells after 6-minute MNase digestion, followed by either mock, CENP-A, or CENP-C N-ChIP. Unbound chromatin was used for bulk chromatin. Representative AFM (A) and TEM (B) images 
of either mock, bulk chromatin, CENP-A chromatin, or CENP-C chromatin showed that CENP-C complex is a large polygonal structure. (C) Nucleosomal height was quantified for either bulk chromatin, CENP-A, or CENP-A nucleosomes associated with CENP-C complex. The mean height with standard error is shown, as well as their distribution. Robustly kinetochore associated CENP-A nucleosomes were significantly taller than weakly or not bound CENP-A nucleosomes (2-sided t test $p<2 \cdot 6 \cdot 10^{-18}$ ). (D) A model showing how 4-6 CENP-A nucleosomes associate with the inner kinetochore, including a stretch of 230-bp of naked DNA that is refractory to MNase digestion.

\section{Figure 5 - CENP-C overexpression did not increase mitotic double strand DNA breaks}

Representative images of either wild-type or CENP-C overexpressing HeLa cells. HeLa cells were transfected for three days and synchronize to early G1 prior to fixation and staining for CENP-C (green), CENP-A (red), $\gamma \mathrm{H} 2 \mathrm{~A} . \mathrm{X}$ (cyan), and DAPI (grey). No difference in number of $\gamma \mathrm{H} 2 \mathrm{~A} . \mathrm{X}$ foci was observed between the two samples. Arrow highlight lagging chromosomes.

\section{Figure 6. New CENP-A loading impaired upon CENP-C overexpression}

(A) Western blot comparing wild-type versus CENP-C ${ }^{\mathrm{OE}}$ conditions for RNAP2, CENP-C, and CENP-A levels at early G1. (B) Quantification of RNAP2 and CENP-A levels. (C) Schematic of experimental design. (D) Colocalizing immunofluorescent signal for CENP-A and TMR-Star are collected and the intensity of both foci is measured as well as background directly neighboring the foci to determine the ratio TMR-star signal over total CENP-A signal. (E) De novo CENP-A incorporation was assessed by quench pulse-chase immunofluorescence. After old CENP-A was quenched with TMR-block, newly loaded CENP-A was stained with TMR-Star and foci intensity was measured over total CENP-A foci intensity. Inset is a 2x magnification of the dotted box in each respective image. (F) Quantification of de novo CENP-A loading by measuring the ratio of TMR-Star signal over total CENP-A signal.

Figure 7. CENP-C overexpression leads to increased mitotic defects, which can be rescued with CENP-A CTD mutants 
(A) Three days of ectopic overexpression of CENP-C, which were synchronized to M phase, resulted in dramatic increase in mitotic defects compared to wild-type cells. The C-terminal tail of CENP-A is essential for recruitment of CENP-C. We reasoned that to rescue the mitotic defect of CENP-C overexpression by co-expressing histone H3 with the $\mathrm{C}$-terminal tail of CENP-A $\left(\mathrm{H}^{\mathrm{CpA} \text { CTD }}\right)$ or CENP-A lacking its C-terminal tail (CENP-A $\left.{ }^{\triangle \mathrm{CTD}}\right)$. (B) Mitotic defects were quantified. We observed that the level of both multipolar spindle (red) and multipolar spindle with lagging chromosome (orange) were reduced to wild-type levels. 

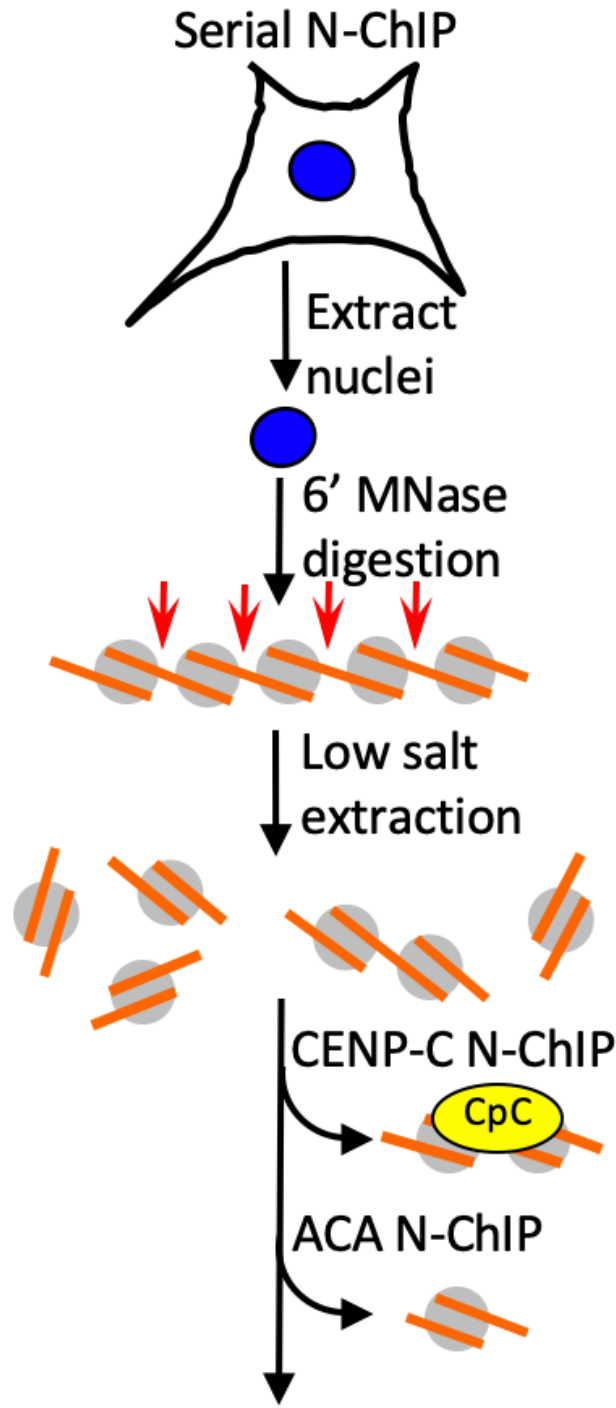

Unbound -

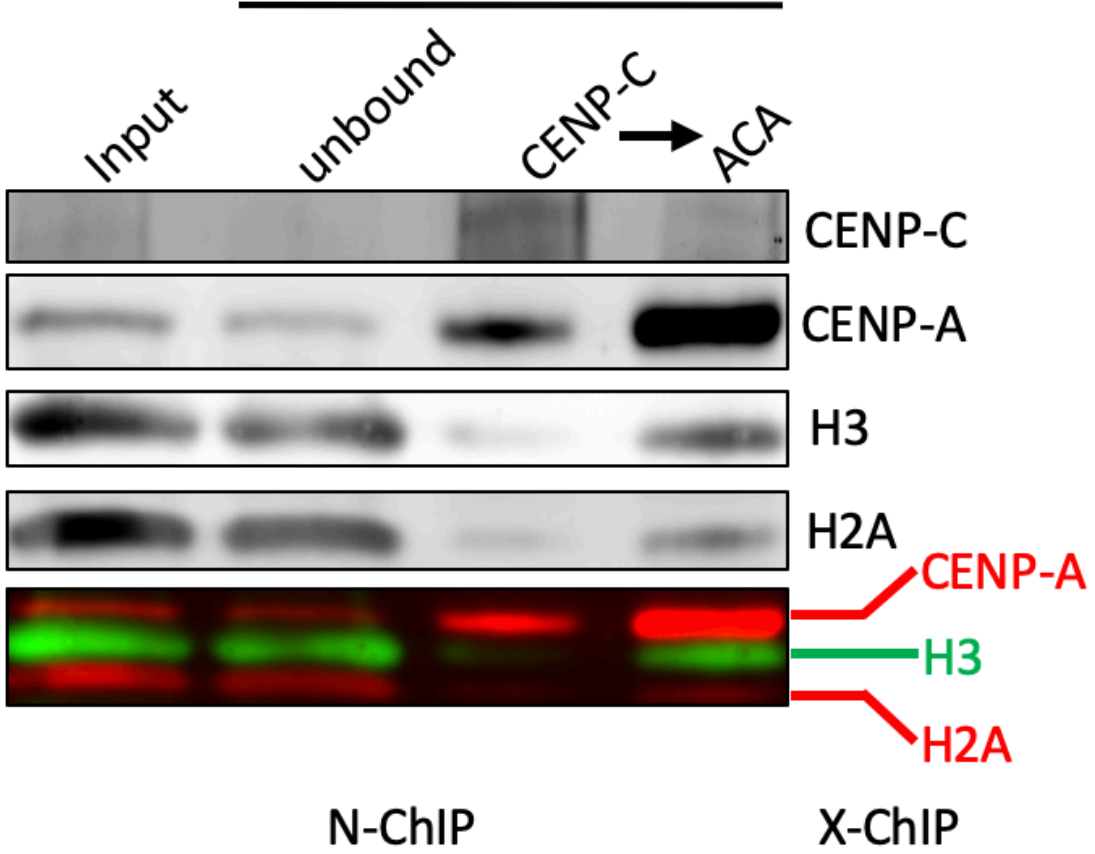

C.

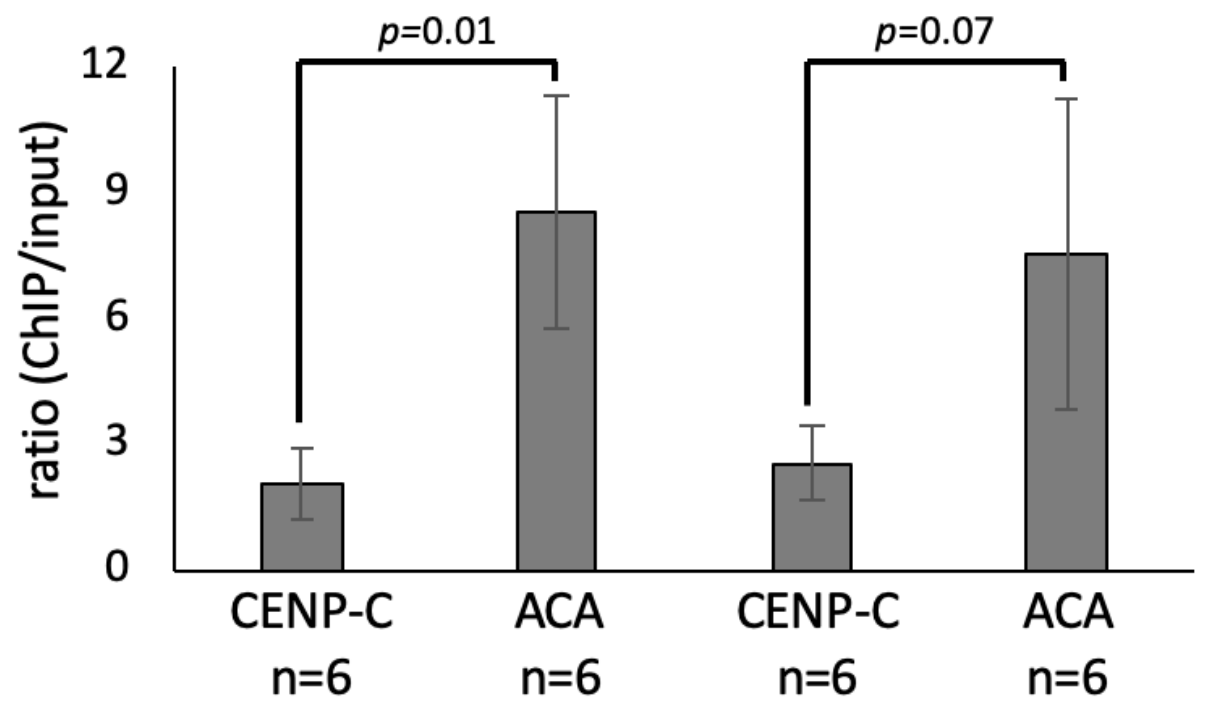

D.

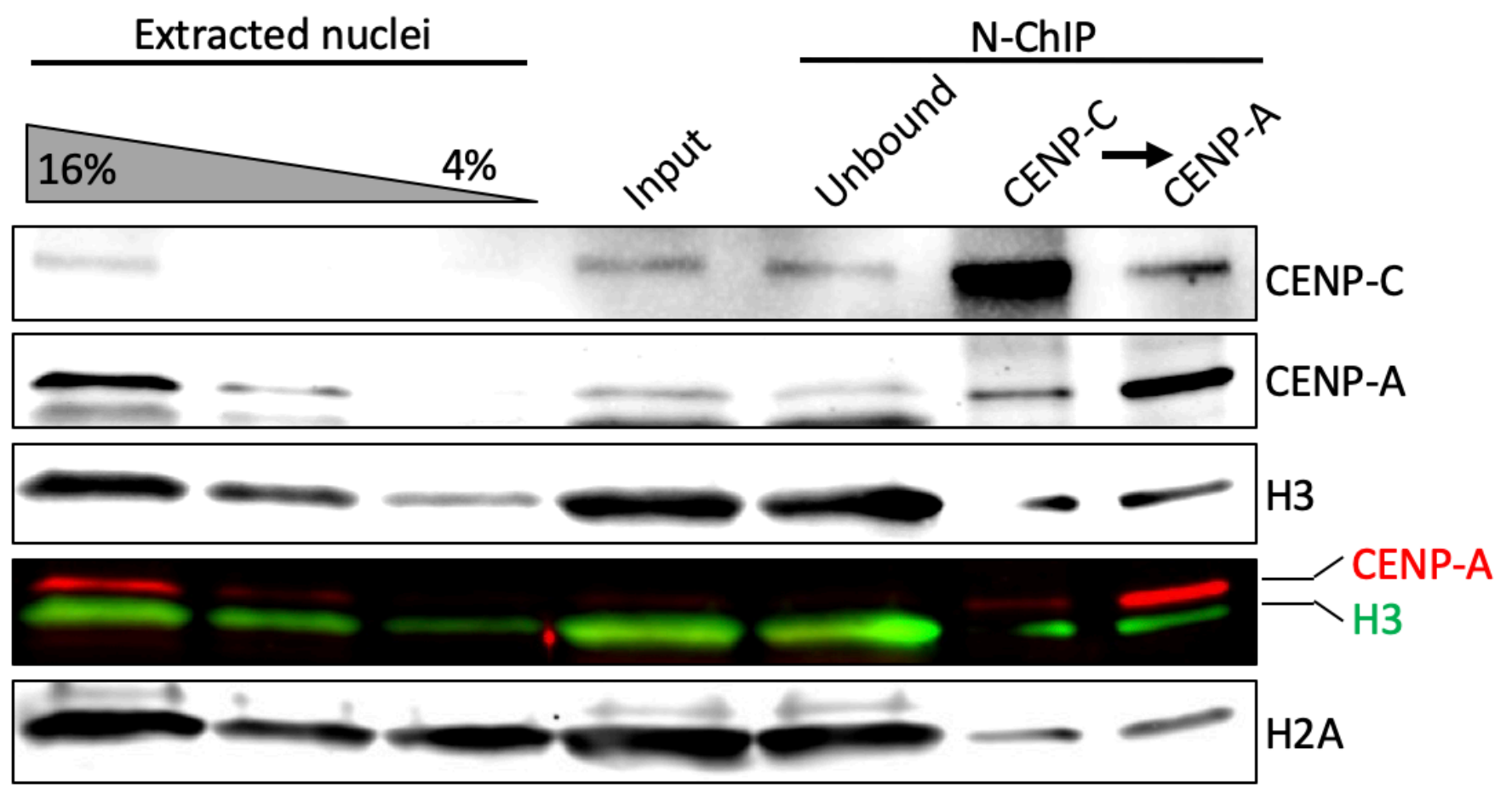


bioRxiv preprint doi: https://doi.org/10.1101/604223; this version posted October 24,2019 . The copyright holder for this preprint (which was not certified by peer review) is the author/funder. This article is a US Government work. It is not subject to copyright under 17 USC 105 and is also made available for use under a CCO license.

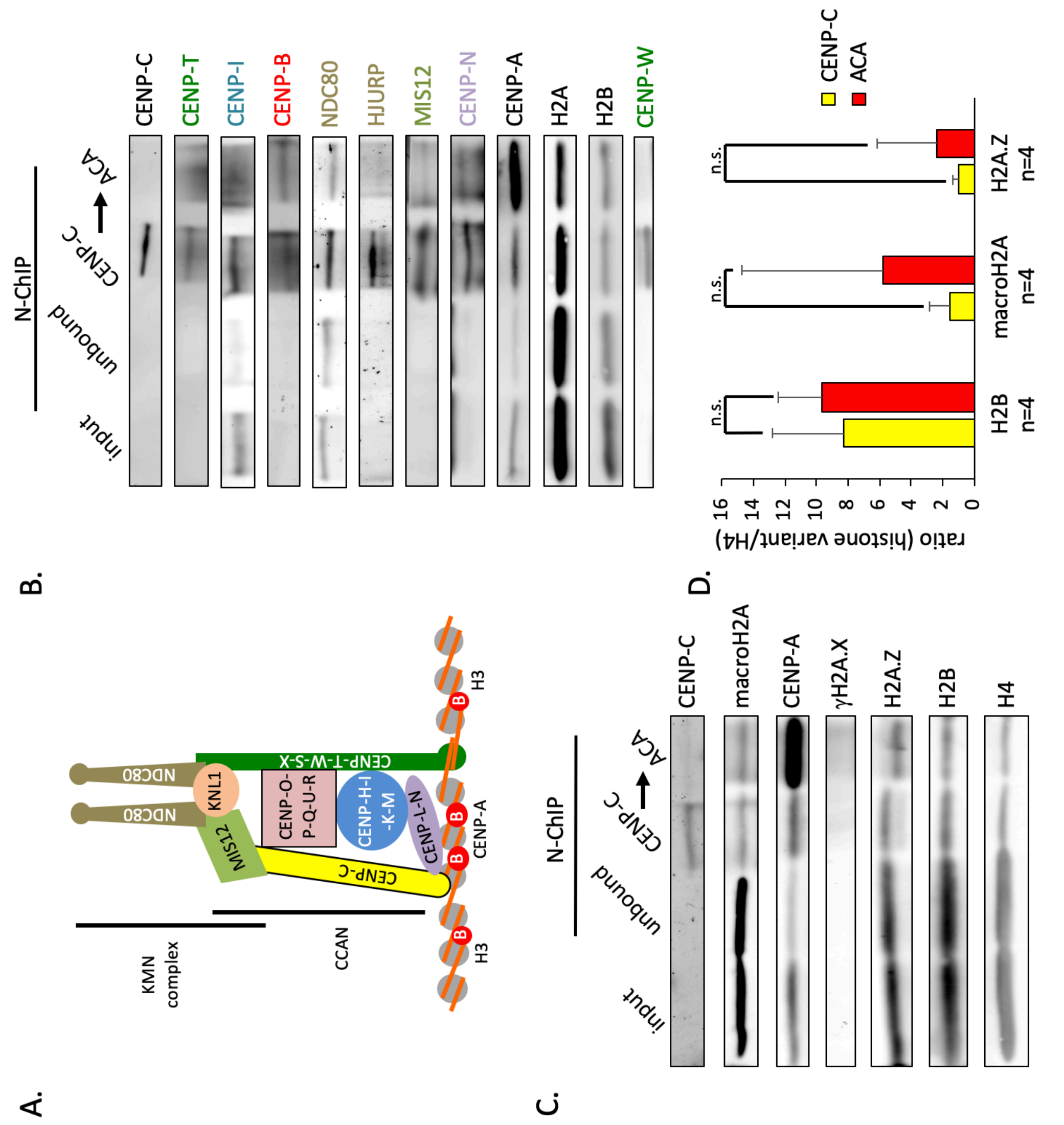


bioRxiv preprint doi: https;//d.oj.org/10.1101/604223; this vereion posted October 24, 2019. The copyright holdep for this preprjnt (which was not certified by peer review) is the author/funder. This anticte is o'US Governmenturork. It is not subject to c6pyrigkt under 17 USC 965 and is also

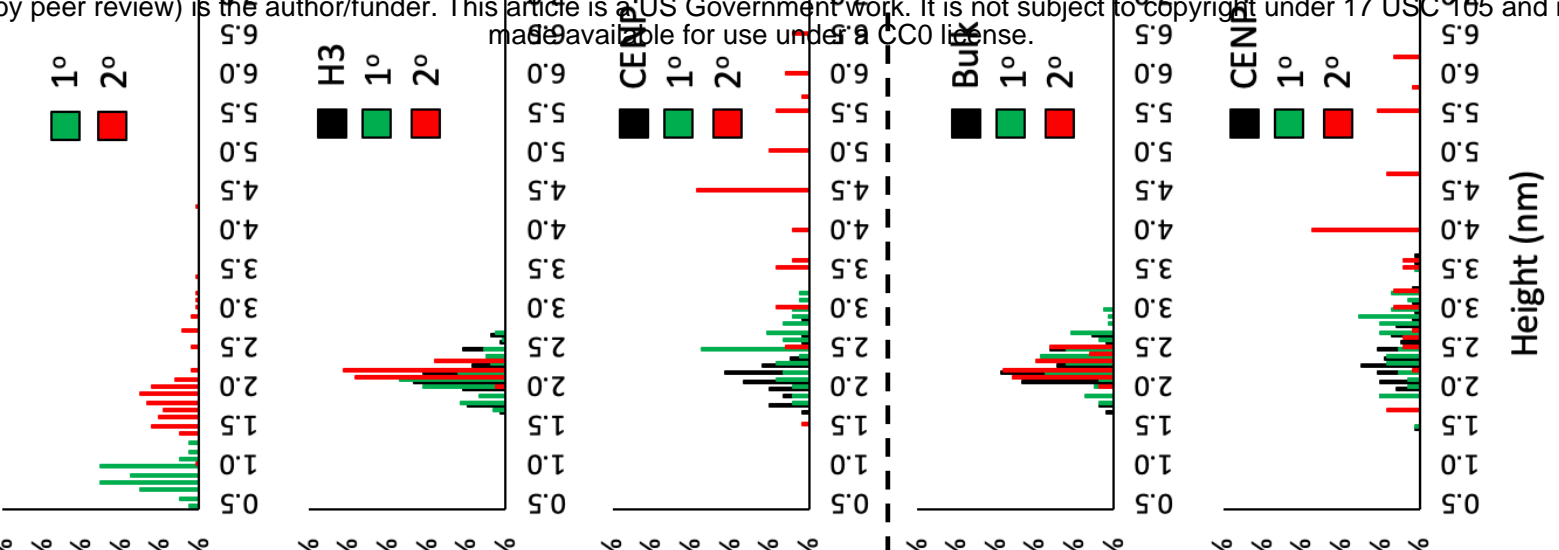

j

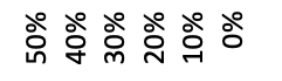
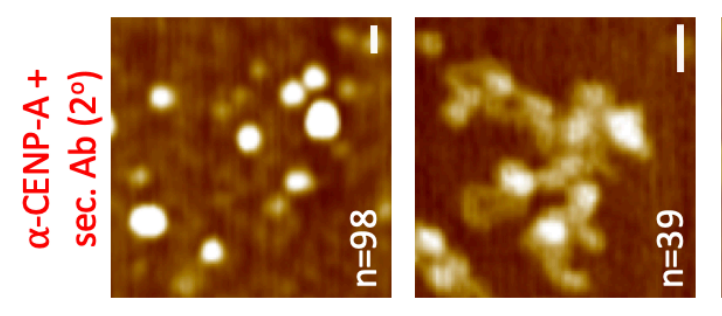

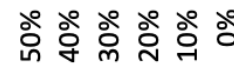

I

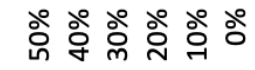
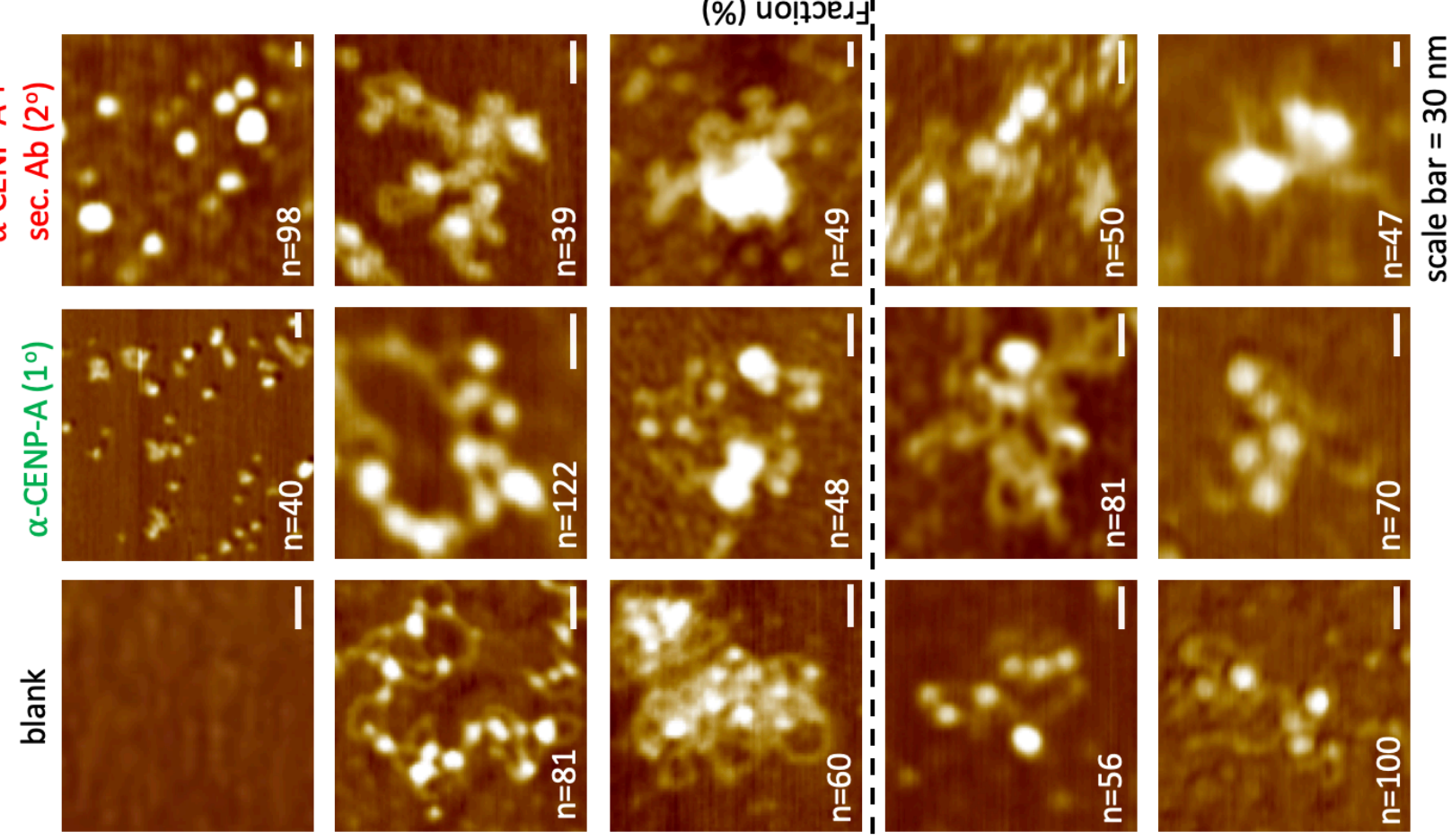

$\frac{\text { 竞 }}{\frac{\pi}{0}}$
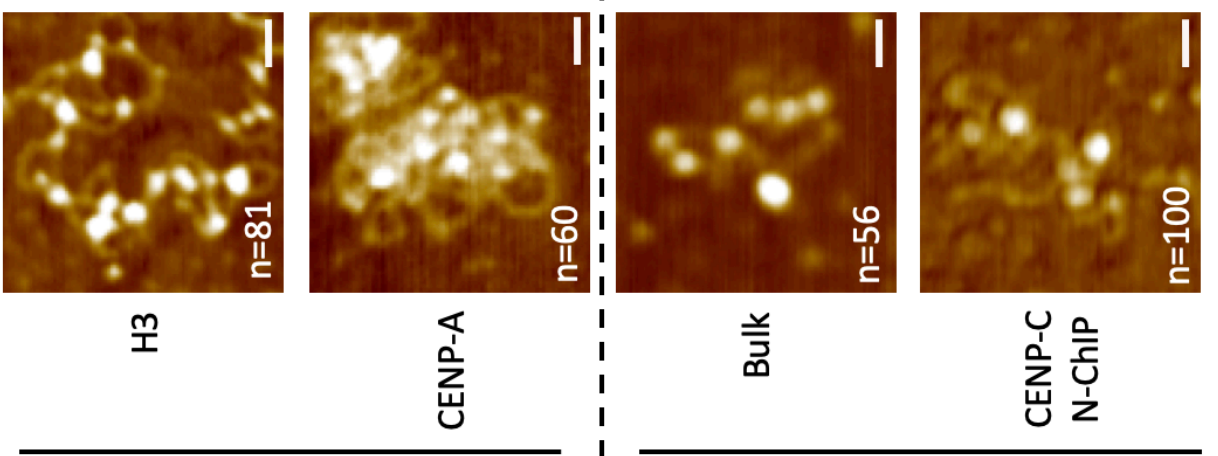

0ג7!n UI

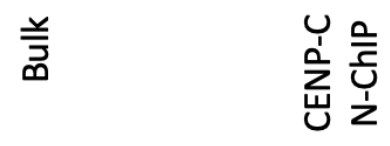

on!̣n ul

$\infty$
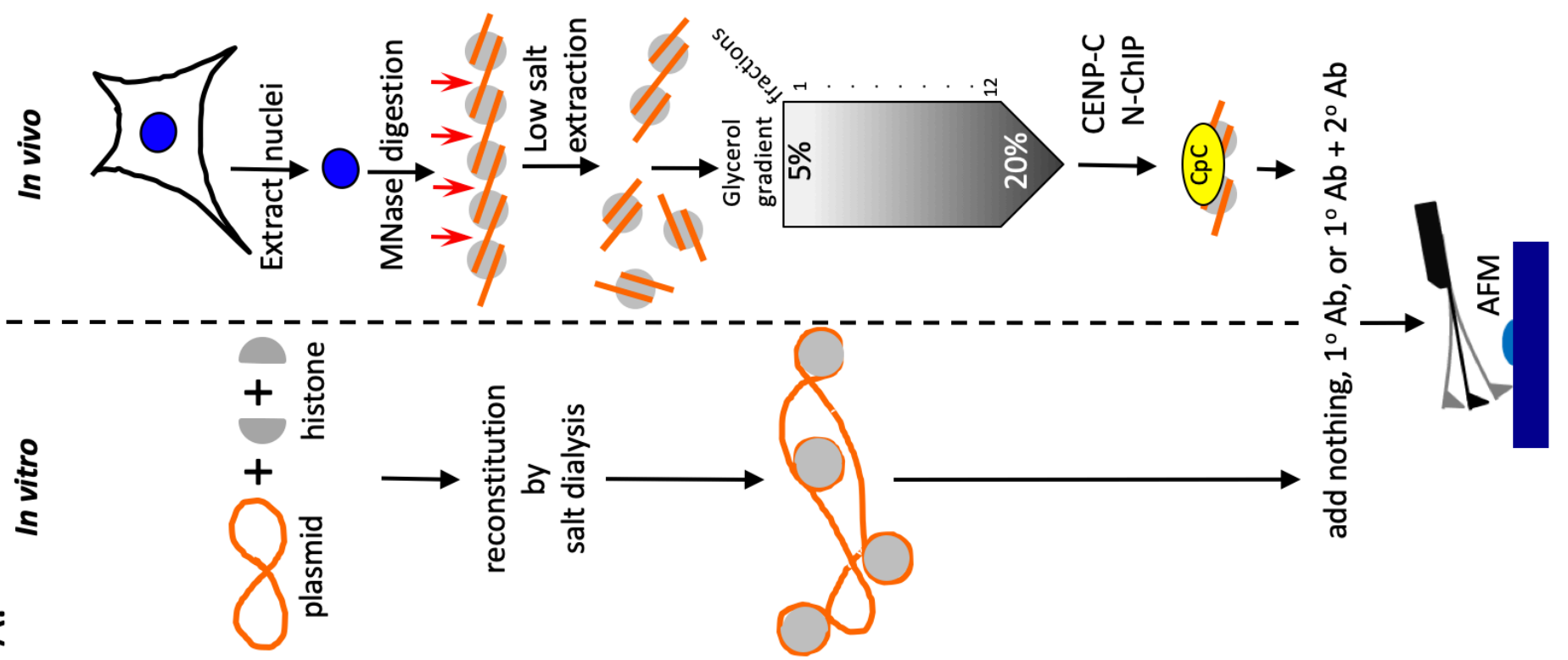

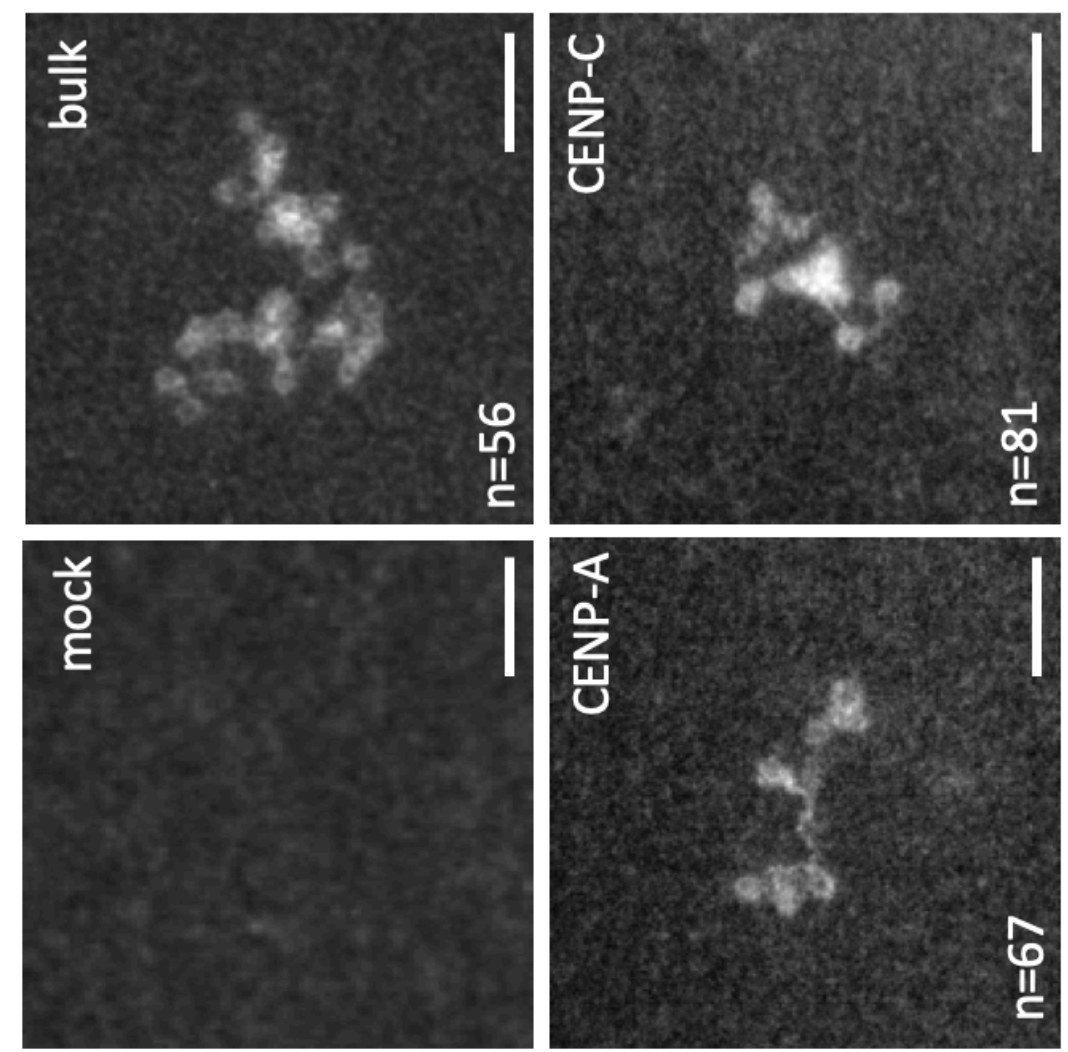

$\dot{\infty}$
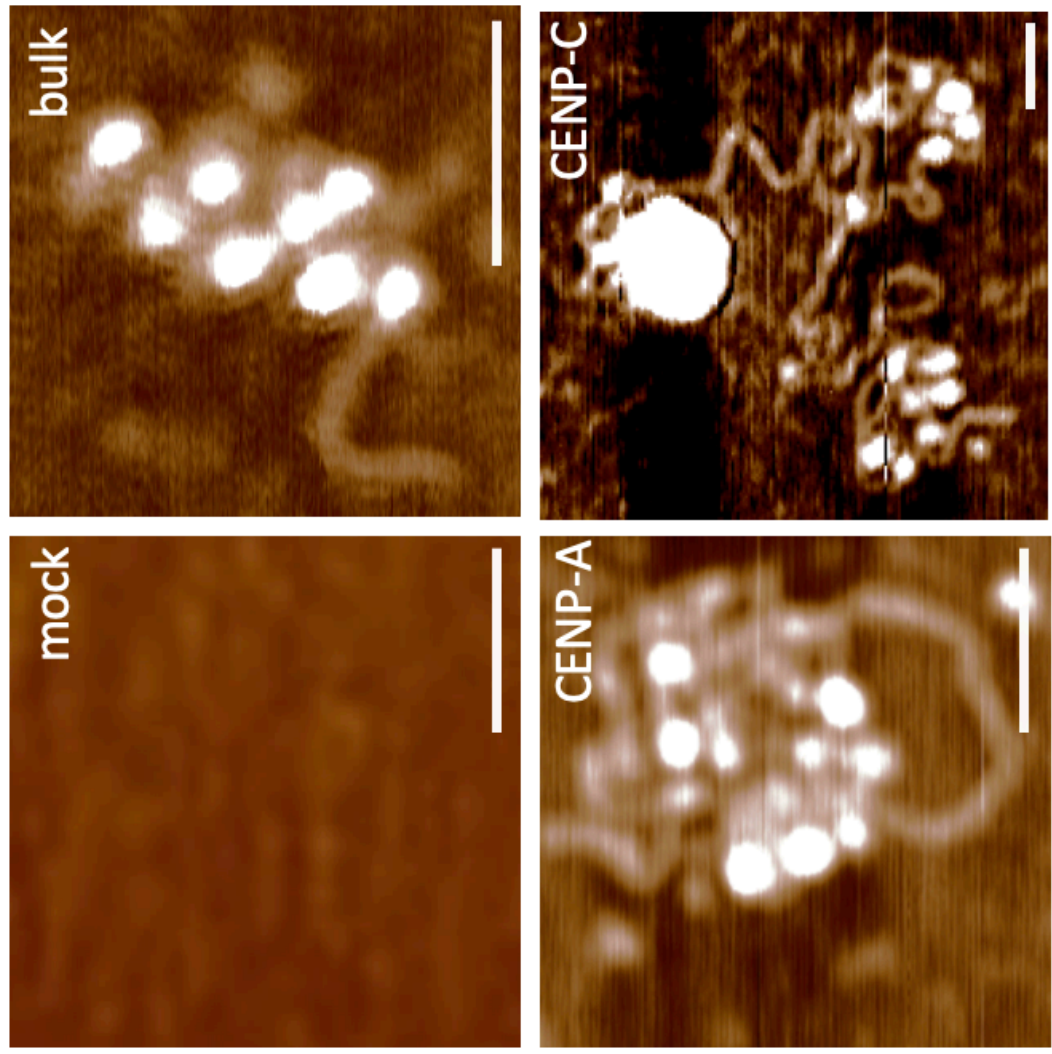

$\dot{<}$
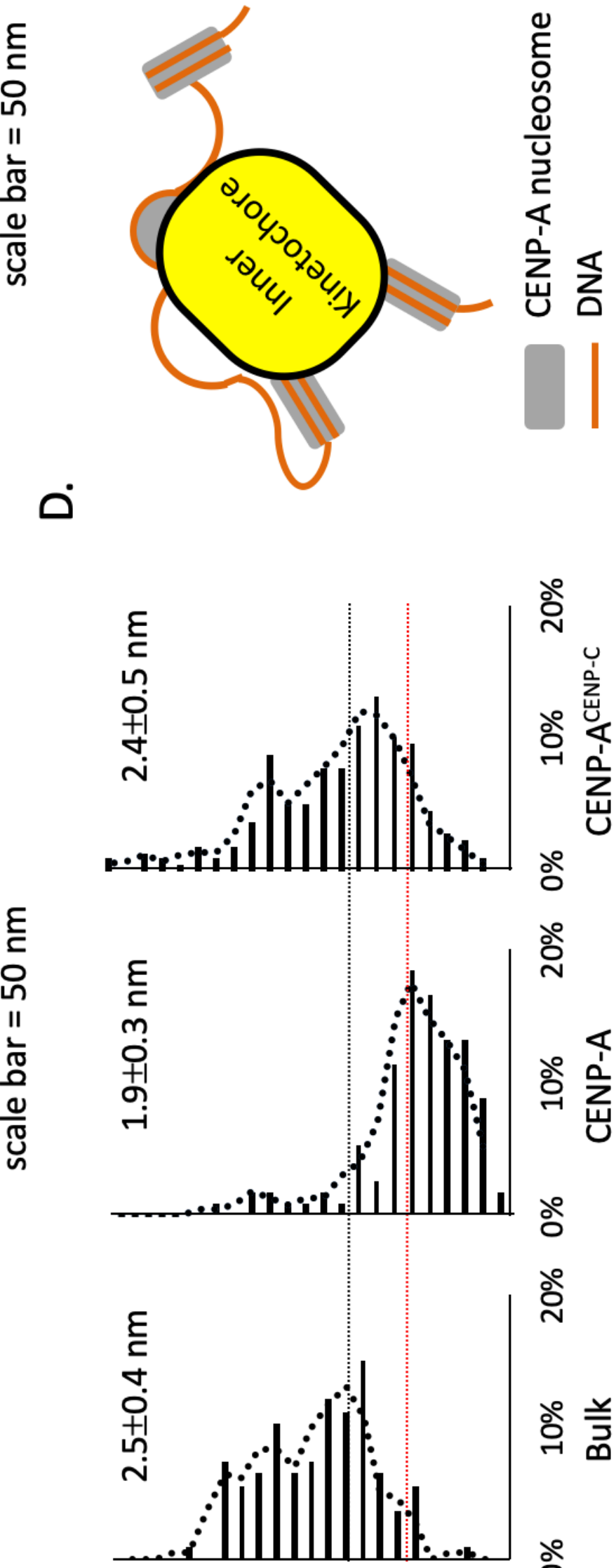

ণัญ

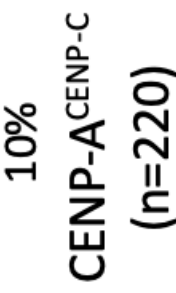

ஓ̊

ઠั

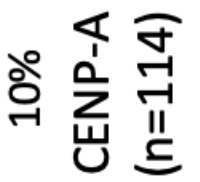

ஃ̊

○ั่

육 호 옳

১े 
A.

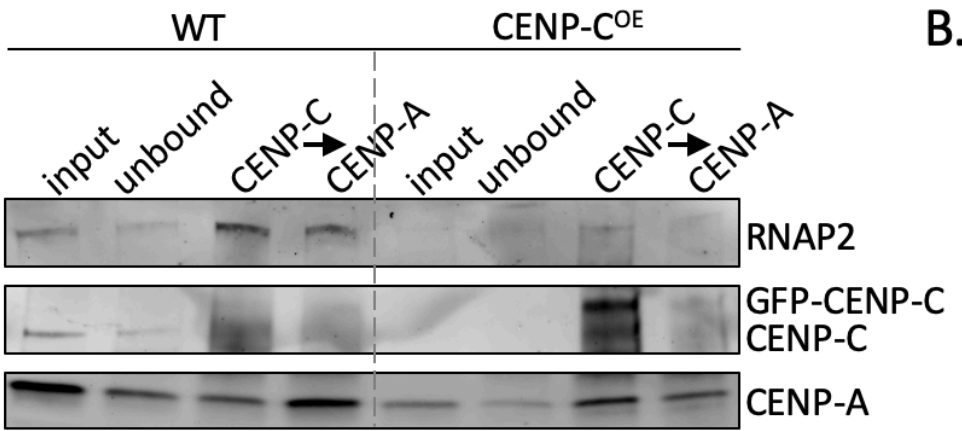

C.
B.

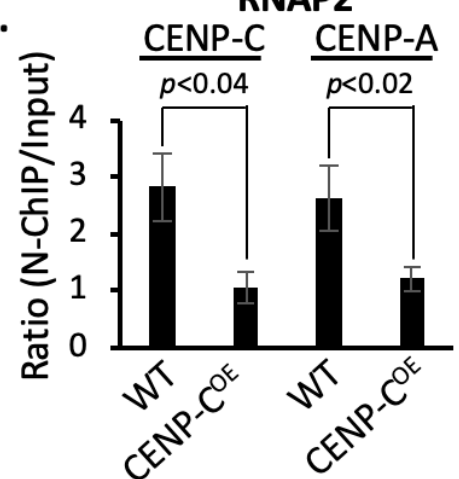

CENP-A

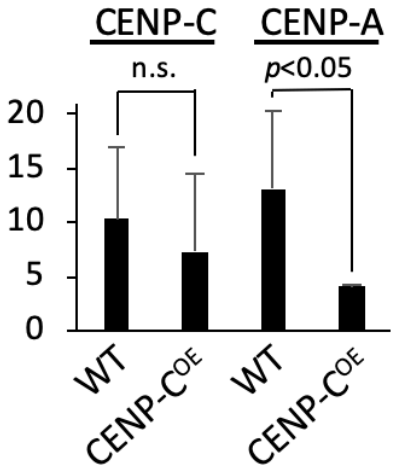

D.
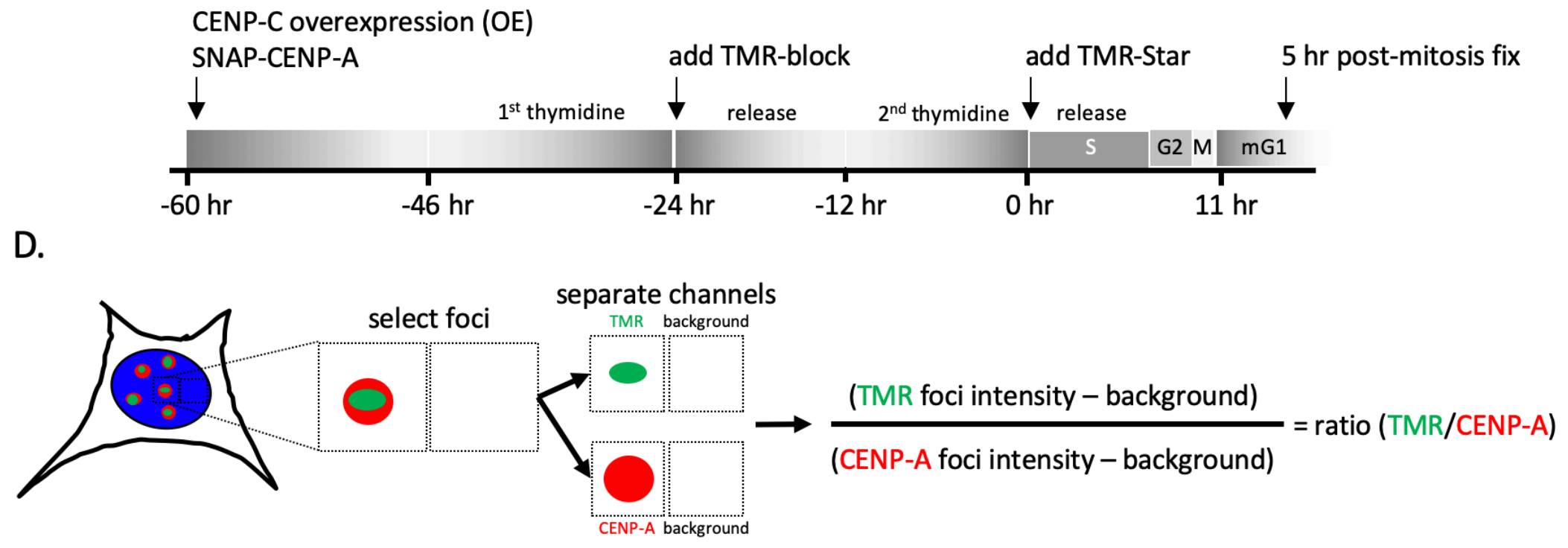

E.
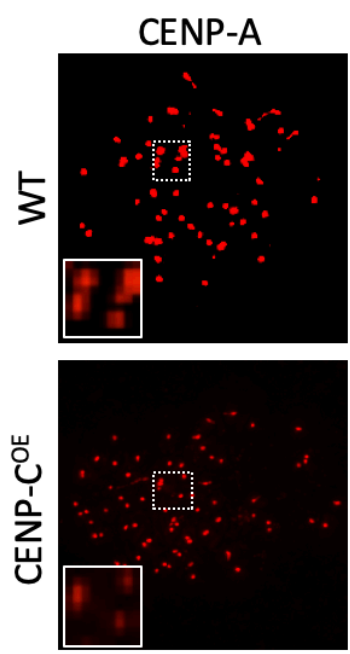

total CENP-A
TMR-Star
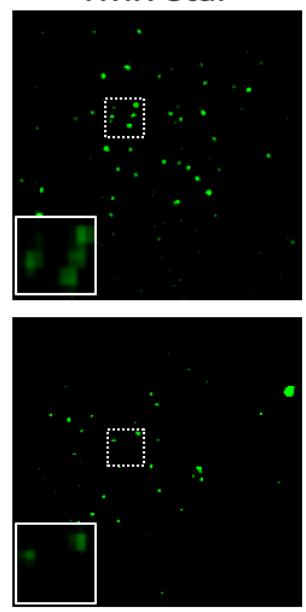

new CENP-A merge
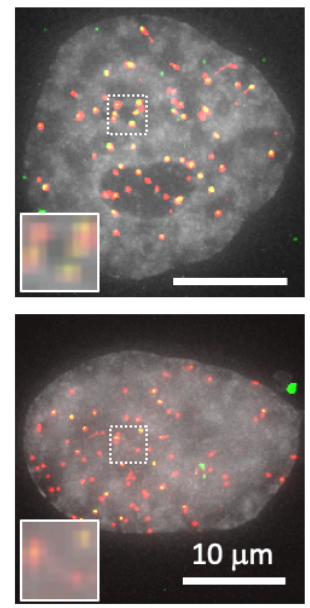

mid G1
F.

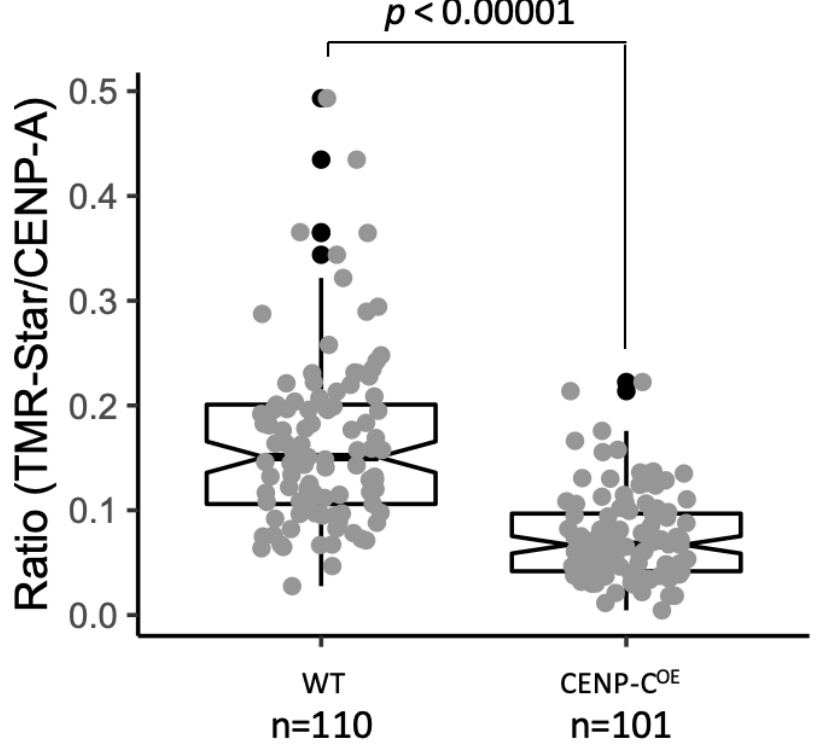


bioRxiv preprint doi: https://doi.org/10.1101 3 4223; this version posted October 24, 2019. The copyright holder for this preprint (which was not certified by peer review) is the author/funde. This article is a US Government work. It is not subject to copyright under 17 USC 105 and is also
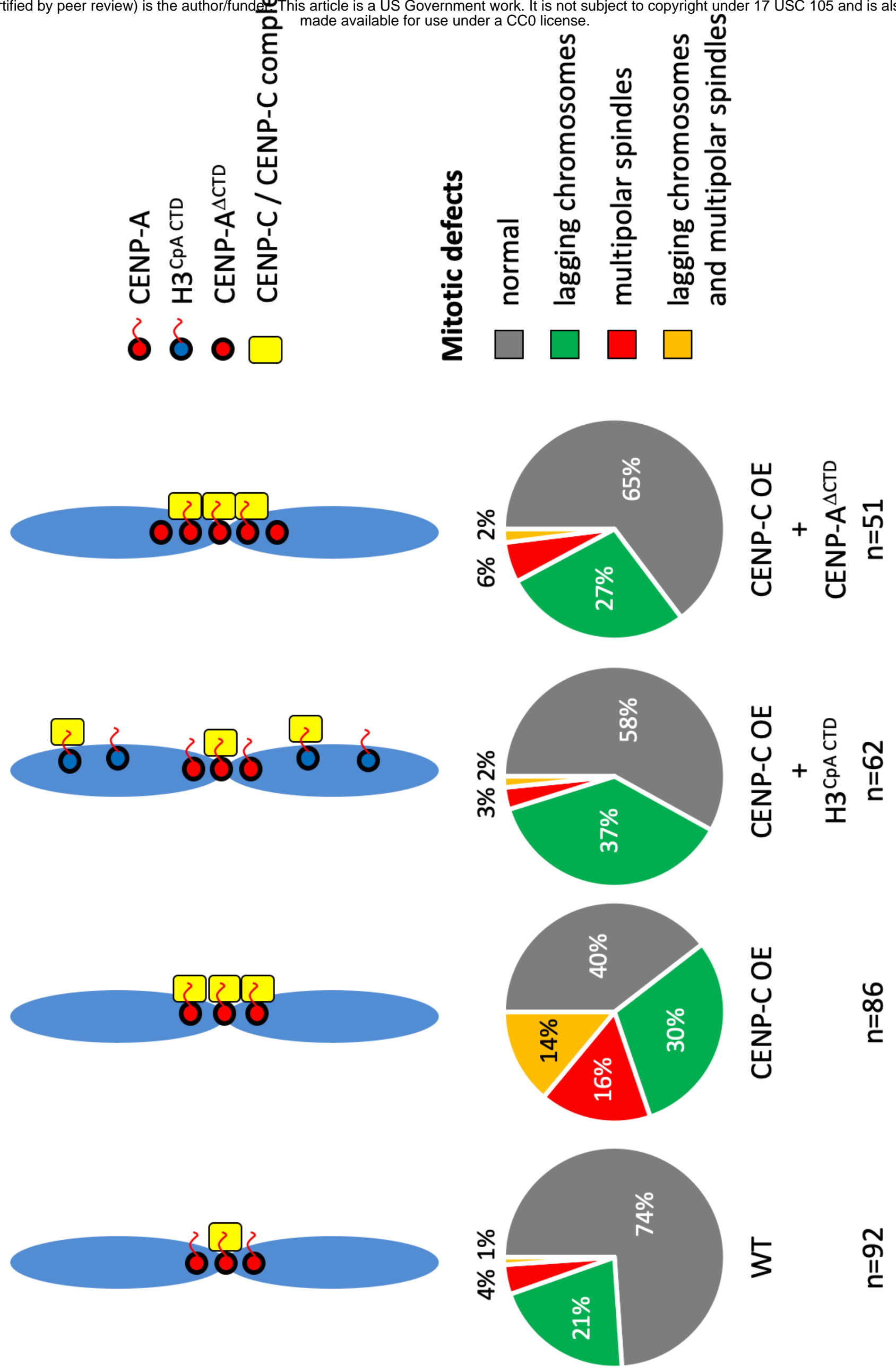

$\dot{4}$ 